Revista Chilena de Antropologia $N^{\circ} 5,1986,17-54$

Facultad de Filosofía, Humanidades y Educación

Universidad de Chile, Santiago, Chile

\title{
La secuencia de Myriam Tarragó para San Pedro de Atacama: Un test por termoluminiscencia
}

\author{
José Berenguer, Angel Deza, \\ Alvaro Román y Agustín Llagostera.
}

\section{RESUMEN}

A fin de colocar a prueba la secuencia cultural propuesta por Myriam Tarragó (1968) para el estadio Cerámico de San Pedro de Atacama, se fecharon por termoluminiscencia $\mathbf{4 0}$ cerámicas -muchas de ellas representativas de cada una de las ocho fases definidas por la autora- excavadas por Le Paige y otros entre 1955 y 1983. El resultado es una nueva cronología respaldada por numerosos fechados absolutos y una actualizada secuencia cultural basada en la de Tarragó. Esta experiencia puede repetirse en lugares con problemas similares, dando, de paso, un renovado uso a colecciones cerámicas depositadas por largó tiempo en museos y otras instituciones.

\section{INTRODUCCIÓN}

Aunque los primeros hallazgos arqueológicos en San Pedro de Atacama anteceden en muchas décadas a las investigaciones del R.P. Gustavo Le Paige, son éstas en verdad las que inician la problemática arqueológica del Salar de Atacama. Desde 1955 hasta el momento de su muerte, en 1980, Le Paige descubrió y excavó numerosos sitios arqueológicos, dando origen a una de las muestras de restos prehispánicos más rica y completa del área Centro Sur Andina. El enorme interés que estos hallazgos despertaron y siguen despertando en círculos académicos nacionales y extranjeros, se refleja en la amplia variedad de proyectos que se han diseñado para investigar los materiales y publicarlos'.

\footnotetext{
${ }^{1}$ Una síntesis de los estudios atacameños ha sido publicada recientemente por Bente
} 
Sin embargo, a 30 años de los comienzos de las investigaciones de Le Paige, hay varios problemas básicos que son críticos en la arqueología del salar. De todos ellos, quizás uno de los más graves - por sus implicancias en otros campos de la investigación- es el relativo a la cronología y secuencia del estadio Ceramico ${ }^{2}$.

En el reciente Simposio de Arqueología Atacameña, organizado por la Universidad del Norte (enero de 1983), diversas ponencias analizaron este estadio cultural - particularmente al complejo San Pedro- en términos de desarrollo regional, adaptación ecológica, evidencias de interacción con otras culturas, identificación de indicadores de cambio, ocupación multiétnica de los oasis, cronología de los materiales intrusivos de Tiwanaku y mecanismos de complementariedad económica. Para algunos investigadores, no obstante, fue evidente en esa reunión que tales problemas no pueden estudiarse con suficiente rigor teniendo como base la ahora simplificada secuencia de 1963 (OrELLANA, 1963) o las que derivaron posteriormente de ella (Congreso, 1963; Orellana, 1964; NéÑEz, 1965).

Es posible que esta vieja secuencia continúe usándose, porque fue ratificada por acuerdo de todos los arqueólogos en el Congreso Internacional de Arqueología de San Pedro de Atacama, en 1963. Pero un acuerdo - por consensual que sea- no es garantía de vigencia, sobre todo cuando han pasado más de 20 años. Como era esperable, la cronología propuesta en aquel entonces varió con las investigaciones posteriores (LE PAIGE, 1963 a y b; Núñez, 1966); de hecho, hoy la cronología que se maneja para el complejo San Pedro se inicia hasta 900 años más temprano de lo que se pensaba en la década del sesenta (Le Paige, 1976, p. 145). Resulta obvio, por lo tanto, que mantener el mismo número de fases (tres o cuatro) para un lapso que ahora cubre con largueza más de 2000 años, es simplificar la historia cultural atacameña. Todo esto sin considerar, desde luego, los nuevos hallazgos de Toconao Oriente, Coyo Oriente, Tchaputchayna, Tulor1, Solcor-3 y Quitor-6, que han puesto de manifiesto la complejidad del desarrollo local.

En otras palabras: ¿cómo es posible abordar problemas de la envergadura de

Bittman (1984), en donde se citan los principales trabajos sobre la arqueología del salar de Atacama.

${ }^{2}$ De un total de más de 5000 tumbas excavadas en diferentes cementerios del salar de Atacama, sólo seis han sido fechadas por C-l 4 (datos hasta marzo de 1983):

Toconao Oriente

Quitor-5

Quitor-6

Solor-6

Solor-4*

Quitor-9

Solor-4*

*Pertenecen a una misma tumba.

$\begin{array}{rr}2530 & \text { a.p. } \\ 1715 \pm 80 \text { a.p. } & 580 \text { a.C. } \\ 1700 \pm 150 \text { a.p. } & 200 \text { d.C. } \\ 1650 \pm 150 \text { a.p. } & 250 \text { d.C. } \\ 970 \pm 75 \text { a.p. } & 300 \text { d.C. } \\ 900 \pm 80 \text { a.p. } & 980 \text { d.C. } \\ 770 \pm 65 \text { a.p. } & 1050 \text { d.C. } \\ & 1180 \text { d.C. }\end{array}$


Mapa: San Pedro de Atacama y Toconao en el área Centro-Sur-Andina.

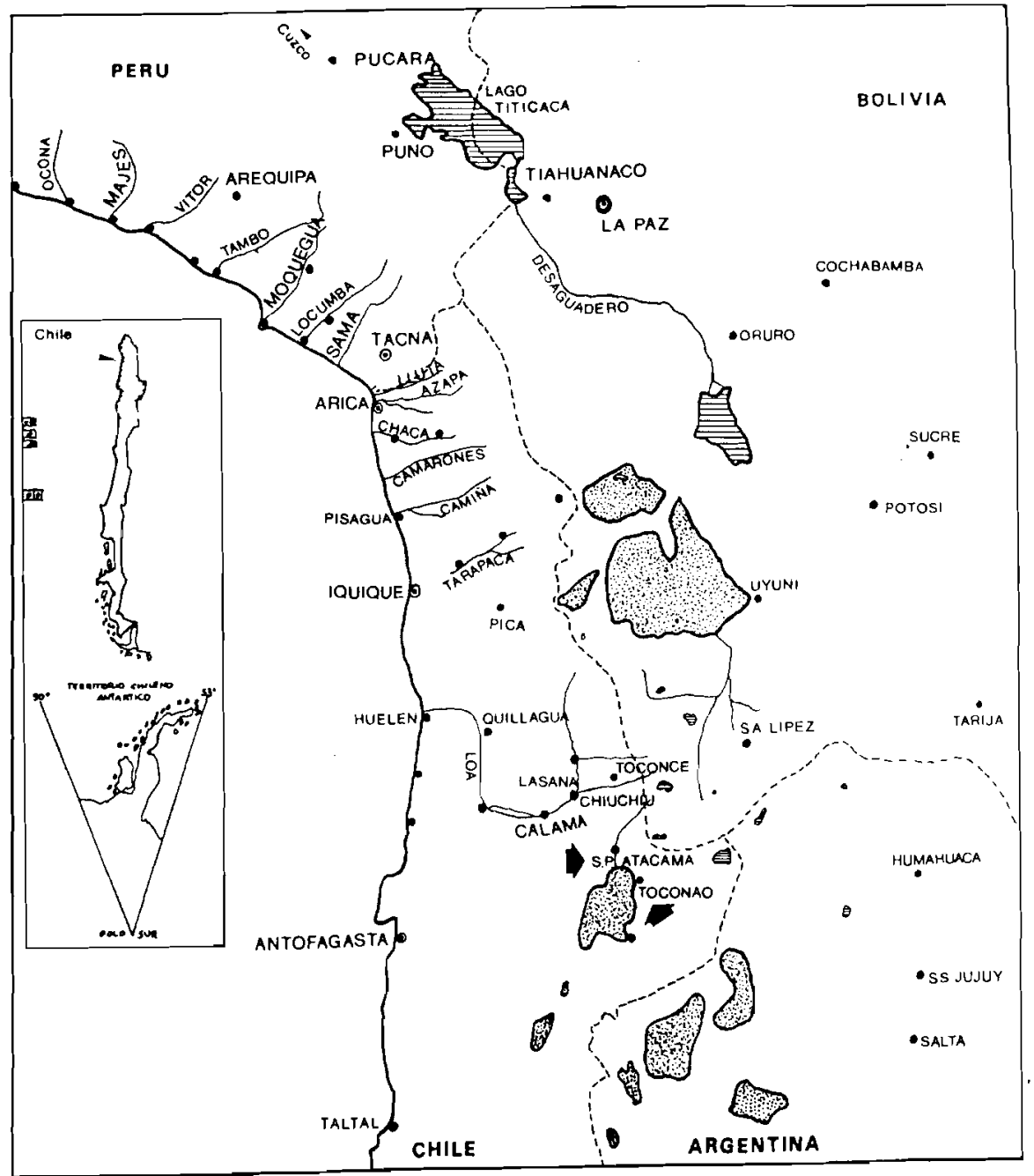

los discutidos en el mencionado simposio, sin contar con una más detallada secuencia histórica de la región? La solidez de esta suerte de "andamio" cronológico-cultural es vital para establecer la dirección del cambio cultural en términos de eventos y procesos.

\section{Un Test para la secuencia de Myriam Tarragó}

Curiosamente, esta secuencia más detallada existe, pero no ha sido suficiente- 
mente considerada por los investigadores. Nos referimos a la secuencia de ocho fases propuesta por Myriam Tarragó en 1968 (Cuadro 1) ${ }^{\mathbf{9}}$. Como se sabe, esta secuencia fue el resultado de secuencias parciales por sitio, que la autora realizó sobre la base de una seriación de los ajuares de 1415 tumbas provenientes de 43 cementerios de San Pedro de Atacama, y de un minucioso estudio de los apuntes de campo de Le Paige. La investigación comprendió primero el análisis y descripción de la alfarería local; enseguida, el estudio y registro de los ajuares y of rendas asociados a cada tumba; y finalmente, el análisis e interpretación de los elementos culturales asociados en cada tumba y su ordenamiento en series secuenciales. En esta última etapa de su trabajo, Tarragó (ibíd.: 124-126) estableció la frecuencia de aparición y formas de asociación de la cerámica, de otros artefactos del conjunto funerario y de los elementos foráneos ${ }^{4}$.

La secuencia de Myriam Tarragó no carece, por cierto, de limitaciones. Tal como lo señala la propia autora, la fase II "no aparece bien representada por medio de ajuares numerosos y bien documentados por unidad de tumba" (algo similar opinamos nosotros de las fases VI y VII). Además, como todos los datos de sitios provienen de lo que se conocía hasta noviembre de 1964 (ibíd.: 127), requiere ser actualizada con los hallazgos posteriores, especialmente con los de Toconao Oriente (Le PAIGe, 1973). Otra limitación de esta secuencia, es que fue estructurada en importante medida a través del hito cronológico representado por los materiales intrusivos de Tiwanaku (ibíd.: 126), y sabemos por Elías

\footnotetext{
${ }^{3}$ Originalmente las llamó "series", pero posteriormente ha usado el término "fase" (TARraGó, 1976: 50), denominación que preferimos.

${ }^{4}$ Resumidamente, las 13 asociaciones son las siguientes: 1) Rojo Pulido solo; 2) Rojo Pulido y vasijas grandes alisadas ("urnas"), presencia de pipas similares a las de Candelaria, tembetás, hachas y mazas de piedra, collares de turquesa y malaquita, y capachos; 3 ) Rojo Pulido y Rojo Pulido atípico, probablemente asociados a vasija negro y blancoamarillo sobre rojo pulido similar a Candelaria; 4) Rojo Pulido y Negro Pulido I, III, V y $\mathrm{XI}$, y "urnas", presencia de pipas similares a las de Candelaria, tembetás, hachas y mazas de piedra, collares de turquesa o malaquita, y capachos; 5) Negro Pulido con predominio de forma III, formas I, V, XI, IV (a veces en proporción considerable), X (base cónica), "urnas", $\mathrm{X}$ con decoración "A", presencia de pipas similares a Candelaria, tembetás, hacha y mazas de piedra, collares de turquesa y malaquita, y capachos; 6) Negro Pulido con predominio de formas VII y IV, formas VI, IX, II, X decoración “A/B" y "B" y tipo Gris Grueso Pulido, notable disminución de tembetás, algunas hachas de piedra, hachas simbólicas, collares de liparita, capachos, cestos policromos y tallados en madera con iconografía de Tiwanaku "puro"; 7) Negro Pulido y Negro Grabado, formas VII, IV, VI, IX, II, XA/B, XB, posible tipos Rojo Grabado y Gris Grueso Pulido, hachas y mazas metálicas, capachos y cestos policromos; 8) Negro Pulido y Rojo Grabado, ídem anterior; 9) Negro Grabado sin asociación local o asociada a Gris Grueso Pulido, presencia de capachos; 10) Rojo Grabado sin asociación local o asociada a Gris Grueso Pulido, presencia de capachos; 11) Gris Pulido Grueso, tallado en madera y vasijas Tiwanaku "transformado" o "decadente", disminución de capachos; 12) Pucos a veces con la superficie externa alisada y la externa pulida; 13) "Concho de Vino", "Rojo Violácea" o "Roja Pintada" (para las denominaciones de los tipos cerámicos y de sus formas, véase TARRAGó 1976).
} 


\section{Cuadro I \\ CRONOLOGIA Y SECUENCIA DE MYRIAM TARRAGO \\ PARA SAN PEDRO DE ATACAMA}

I. Cerámica ordinaria. Urnas de base cónica de Solor 6. Se mantiene como hipótesis a la espera de mayor cantidad de datos.

300 d.C.

II. ?

La formulación de una fase con San Pedro Rojo Pulido aislado sin asociación al Negro Pulido, en base a 6 tumbas (asociación l) y a las vasijas de Larrache que carecen de datos de asociaciones de tumbas y se encuentran en un terreno afectado por aluviones, no resulta confiable hasta este momento. Un indicio a su favor sería, tal vez, la tumba 3982 de Quitor 5 y su superposición. Sin embargo, no debe dejarse de lado otros indicios que podrían cambiar la postulación, tales como la existencia de una vasija negra pulida de pare des gruesas, tamaño grande, cuerpo ovoide con base cónica y dos asas verticales cerca del borde, que se encuentra en las colecciones del Museo con procedencia de Quitor 6 y la aparición de una capa de $0,20 \mathrm{~m}$ de espesor con fragmentos de cuatro urnas negras pulidas por encima del nivel de las dos urnas de base cónica de Solor 6, según notas del Padre Le Paige.

III. Grupo de tumbas con San Pedro Rojo Pulido y/o Negro Pulido, "urnas" de base cónica o sin diferenciar y elementos asociados (tipos de asociación 2, 4 y 5).

Relaciones: Tebenquiche, Laguna Blanca, Candelaria.

Comienzos de la influencia de Tiwanaku.

500 d.C.

IV. Grupo de tumbas con San Pedro Negro Pulido, Negro y Rojo Grabado y Tiwanaku Puro con sus asociaciones (tipos 6,7 y 8 ).

Relaciones: Tiwanaku Clásico (?). Contacto con Ciénaga II o III en una tumba del Valle del Hualfín, Catamarca.

V. Grupo de tumbas con San Pedro Negro Pulido en disminución, San Pedro Negro y Rojo Grabado, Gris Pulido Grueso y Tiwanaku Transformado (continúa asociación $9,10,11$ ).

800 d.C.

Relaciones: Tiwanaku Expansivo.

VI. Grupo de tumbas sin cerámica o alisado. Último momento del influjo de la tradición Tiwanaku. Desaparición de todos los tipos anteriores.

1000 d.C.

Relaciones: Tiwanaku Decadente. Tal vez con este momento se relacione la aparición de un vaso de tipologia Isla (Jujuy).

VII. Grupo de tumbas sin cerámica o con escudillas alisadas y/o "concho de vino" (tipos 12 y 19).

1300 d.C.

Relaciones: Huruquilla-Yura,

Tilcara-Yavi.

V1II. Grupo de tumbas con materiales inkaicos.

1500 d.C.

Relaciones: Inka.

Fuente: M. Tarragó (1968: 140-141). 
Mujica (Ms.) que la cronología y secuencia de esa cultura altiplánica se encuentran hoy sujetas a muchas reservas.

Con todo, nuestra impresión es que la secuencia de Myriam Tarragó entrega un marco cronológico-cultural más apropiado para el género de inferencias que se está intentando últimamente $y$, por supuesto, mucho más pormenorizado que el que ofrecen las otras secuencias elaboradas en los años sesenta.

El problema, entonces, podría sintetizarse en una pregunta: ¿cómo hacer para que la secuencia de Myriam Tarragó resulte más confiable para los arqueólogos y pueda usarse como una herramienta de trabajo en los próximos años, considerando además que, al estar basada en datos de 1964, podría hacérsele un cargo de obsolescencia similar al hecho a las otras secuencias?

Una manera de colocar a prueba esta secuencia es realizar un amplio programa de fechamientos por radiocarbón (C-14) de los contextos funerarios más característicos. De esta manera, no sólo se afina la cronología, sino también la posición relativa de cada fase respecto de las otras. Pero un programa de esta naturaleza precisaría de una gran cantidad de nuevas excavaciones (lo que desde ya sería largo y costoso), con el agravante de que no existe ninguna garantía de que tales excavaciones provean materiales orgánicos para el fechamiento y menos que rindan materiales relevantes para cada una de las ocho fases culturales.

Considerando esta limitación y tomando en cuenta además que la mencionada secuencia está basada esencialmente en materiales cerámicos, la alternativa que propusimos fue fechar por termoluminiscencia (TL) varias cerámicas funerarias depositadas en el Museo Arqueológico R.P. Gustavo Le Paige, que fueran representativas de las fases definidas por Myriam Tarragó. Propusimos también actualizarla en alguna medida con los hallazgos posteriores a 1964 .

En este informe se dan a conocer los resultados del test (para una descripción del uso arqueológico del método de fechamiento por TL, véase GarcíaBÁrCena, 1974; también Castro et al., 1979).

\section{Procedimientos}

Algunas de las ventajas que, en este caso, ofrece un test por TL sobre otro por C-14 son: $1^{\circ}$ ) el programa de datación por TL permite obtener resultados en un más breve plazo, ya que no precisa de nuevas excavaciones para conseguir muestras; $2^{\circ}$ ) el costo de la operación es alrededor de un $75 \%$ más barato; $3^{\circ}$ ) las muestras de cerámica para fechamiento se encuentran prácticamente en todas las tumbas; $4^{\circ}$ ) esta última ventaja permite, además, elegir el contexto funerario que se desea fechar con mayor independencia de factores ajenos a los objetivos de la investigación; y $5^{\circ}$ ) al fechar la cerámica, se está poniendo a prueba el fundamento mismo de la secuencia, ya que, como quedó señalado, ésta considera principalmente a la alfarería como indicador de cambio.

Ciertas circunstancias de las muestras, sin embargo, podrían arrojar dudas 
sobre la validez de las dataciones. En efecto, las cerámicas susceptibles de fechar han permanecido en las bodegas y vitrinas del museo por largo tiempo y algunas fueron excavadas hace más de 25 años. Aunque todas cumplen con el requisito de "haber estado a más de $30 \mathrm{~cm}$ de profundidad por lo menos $2 / 3$ del tiempo transcurrido desde su manufactura" (GARCfA-BÁRCENA ob. cit.: 27), si han sufrido un calentamiento posterior a la excavación, podrían ser inservibles para una datación por TL. Este es un problema que, por sus implicancias, fue largamente discutido antes de iniciar la investigación. Pero se concluyó que sólo un calentamiento cercano a los $400^{\circ} \mathrm{C}$ podría inutilizar la muestra; y si tal fuese el caso, dicho calentamiento sería detectado en el proceso de laboratorio (cosa que no ocurrio). De cualquier manera, es altamente improbable que las cerámicas por fechar hayan estado expuestas a una fuente de calor que alcance esa temperatura.

En suma: no existe ninguna dificultad técnica, práctica o teórica que impida fechar con éxito cerámicas excavadas hace largo tiempo.

Selección y estudio de las muestras

Se eligieron 60 cerámicas para fechamiento por TL, según los siguientes criterios no excluyentes entre sí:

1. Por representatividad. Se refiere a aquellas cerámicas seleccionadas por ser "representativas" de alguna fase de la secuencia de Tarragóo por estar asociadas en una tumba a una o más cerámicas representativas en el sentido señalado.

2. Por contexto. Se refiere a aquellas cerámicas seleccionadas por hallarse asociadas en una tumba a elementos locales o "extraños" (intrusivos), considerados como marcadores cronológicos por Tarragó.

3. Por estratigrafia. Se refiere a aquellas cerámicas seleccionadas por provenir de tumbas que se hallaban en relación de superposición con otras.

4. Por actualización. Se refiere a aquellas cerámicas seleccionadas por no estar contempladas en los estudios de Tarragó, sea por simple omisión, sea por provenir de hallazgos hechos con posterioridad a 1964.

5. Por control. Se refiere a aquellas cerámicas seleccionadas por provenir de tumbas fechadas por C-14 o que se planea fechar por ese método ${ }^{5}$.

${ }^{5}$ Hubo varios hechos que redujeron ostensiblemente el número de cerámicas elegibles para datación conforme a los criterios señalados. Como el supuesto básico de la investigación es que la fecha de una vasija sirve para fechar a toda la tumba, se tuvo que seleccionar tumbas que, hasta cierto punto, garantizaran un "contexto cerrado", lo cual hizo inelegibles a aquellas con más de un adulto. Otro ejemplo: mucho de los contextos de tumbas considerados por Tarragó (1968: 134-139) como representativos de sus fases, o diagnósticos por contener "elementos culturales extraños" o intrusivos, no fueron ubicados físicamente en el Museo y algunos tampoco figuraban en la relación de los contextos 
De cada una de las 60 vasijas así seleccionadas, se extrajeron dos fragmentos de aproximadamente $5 \mathrm{~cm}^{2}$, uno para el fechado por $T L$ y otro para un posterior análisis de composición de la pasta. El destino de estos fragmentos fue el siguiente: dos de ellos, correspondientes a aríbalos "rojo-violáceos" tipo "Inka local", fueron datados para calibrar los fechamientos de las otras muestras, ya que su rango de edad entre 510 y 445 años (ca. 1470-1535 d.C.) es conocido por información histórica; 40 fragmentos fueron fechados para colocar a prueba y actualizar la secuencia de Tarragó; y los 18 fragmentos restantes serán procesados más adelante con idéntica finalidad.

Las vasijas que proporcionaron los fragmentos para el programa de datación, provienen de seis cementerios y dos sitios habitacionales excavados por Gustavo Le Paige, Agustín Llagostera, Leandro Bravo, Antonietta Costa y Ana María Barón, entre 1955 y 1983 (véase sección Resultados). Estas vasijas y sus asociaciones cerámicas (si las había) fueron fotografiadas y toda la información concerniente a ellas --incluyendo la relación del contexto, según los excavadores- fue trasladada a una ficha proforma. Durante esta fase de la investigación, se hizo un reestudio de algunos "conjuntos funerarios tipo", particularmente de aquellos que contenían materiales considerados como marcadores cronológicos por Tarragó (e.g. pipas de cerámica, tembetás, hachas y mazas de piedra, hachas y mazas de metal, collares de turquesa y liparita, cestos, capachos, botellas con rostros antropomorfos en el gollete, tallados en madera y cerámica intrusiva). Cuando se estimó necesario, estos materiales fueron fotografiados y descritos. tomándose nota de sus asociaciones culturales en las tumbas.

\section{Obtención de las fechas $T L$}

Cada fragmento fue molido y lavado durante una hora con $\mathrm{HF}(25 \%)$ a $40^{\circ} \mathrm{C}$. El cuarzo fue cernido para obtener granos con diferentes diámetros, desde 100 micrones a $1 \mathrm{~mm}$. Se esparcieron muestras de $5 \mathrm{mg}$ sobre la placa de platino de un lector Harshaw 2000 TLD, con un filtro azul-violeta y a un rango de tempera-

hecha por Le Paige en sus apuntes de campo. Además, no siempre fue posible hallar las cerámicas pertenecientes a tumbas fechadas por C- 14 (e.g. la de Solor-6 y las de Solor-4, véase nota 2). A veces, se lograron ubicar contextos elegibles por contener materiales intrusivos, pero por desgracia carecían de cerámica local para muestreo (e.g. tumba 1357 de Quitor-4 y 358 de Larrache, véase Tarragó, ibíd.: 134). También se dio el caso de tumbas que según la literatura arqueológica o los apuntes de campo de Le Paige, se encontraban en relación de superposición con otras, pero lamentablemente no contenían cerámica para muestreo o ésta no fue ubicada en el Museo (e.g. 3381/3382 de Quitor-5, véase TARRaGó, ibíd.: 130; 1928-9/1930-31 de Quitor-5, véase Tarragó, 1977:54). Y por último, fueron incontables los casos de cerámica elegibles por el criterio de representatividad, pero que, sin embargo, no llevaban marcado el número de la tumba, siendo imposible por esto conocer sus asociaciones funerarias. De todas maneras, algunas de estas últimas fueron seleccionadas. 
tura que se extendió hasta $\operatorname{los} 600^{\circ} \mathrm{C}$. La irradiación fue realizada con una fuente de $10 \mathrm{mCi} \mathrm{Sr}-90$ : la dosis de radiación unitaria fue de $74 \mathrm{rad} / \mathrm{min}$, recalibrada en 1983 (Rom An et al., 1983) y más tarde corregida por el efecto de vida media. Se supuso que la dosis alfa es cero. La dosis beta de la cerámica fue determinada empleando la tabla de Bell (1979). Los valores de concentración de Th, $\mathrm{U}_{\text {y }} \mathrm{K}_{2} \mathrm{O}$ fueron medidos en el Departamento de Activación Neutrónica de la Comisión Nacional de Energía Nuclear, Santiago. La dosis gama fue calculada por dosimetría TL, usando dosímetros de $\mathrm{CaSO}_{4}: \mathrm{Dy}$, que fueron enterrados en Toconao, Quitor y patio del Museo (ayllu de Conde Duque) durante un $\mathrm{mes}^{6}$. Como dosis de radiación cósmica, se usó $15 \mathrm{mrads} / \mathrm{an}$.

El contenido de saturación de agua fue usado tanto para el suelo como para los fragmentos, aunque la humedad de la zona es muy baja.

Para el cálculo de la dosis anual se consideraron los diferentes tamaños de grano de cuarzo. La dosis equivalente y la corrección de supralinearidad son el promedio de los valores obtenidos por extrapolación de la primera y segunda curva de crecimiento de la emisión luminosa. No se estudiaron los fading anómalos.

Las estimaciones de error fueron hechas empleando el método propuesto por Aitkens (1976), suponiendo cero para las incertezas $\sigma_{3}$ (contenido lítico del suelo) y $\sigma_{7}$ (emanación de radón).

\section{Resultados}

El encabezamiento de cada datación incluye la edad de la cerámica en años antes del presente, tomando como base 1980 , el error o desviación estándar y la fecha propiamente tal en términos del calendario actualmente en uso (antes o después de Cristo); el número correlativo de la muestra de cerámica fechaḍa, las siglas del laboratorio de termoluminiscencia, el número de orden de la fecha en dicho laboratorio (UCTL-n) y el número de figura.

El acápite "cerámica" incluye el sitio de proveniencia de la pieza, el número de la tumba o sector del sitio (si lo hay), una denominación descriptiva de la vasija, acabado de la superficie, color (código Munsell) y altura. El acápite "selección" hace referencia al (los) criterio(s) empleado(s) para elegir la muestra, especificándolo(s) en cada caso. A veces, se incluye un acápite "observaciones" para agregar información no contemplada en los acápites anteriores.

Por limitaciones de espacio, no se incluyó el detalle de los contextos fechados, pero éstos - transcritos directamente de los apuntes de los excavadores--se encuentran a disposición de los investigadores para consulta.

${ }^{6}$ En un trabajo presentado en este Congreso (DEZA y Román Ms.), se informa sobre los primeros resultados en dosimetría termoluminiscente en arqueología para nuestro pais. Una parte de esa experiencia se hizo en relación al programa de fechamiento por TL en San Pedro de Atacama.

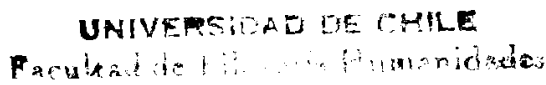

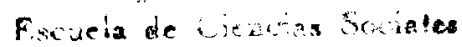

$$
\begin{aligned}
& \text { - BLlOTECA }
\end{aligned}
$$


Ordenadas por tiempo, desde la más antigua a la más reciente, las fechas son las siguientes:

1. $2330(--, \pm 235) 350$ a.C.

muestra 20 (UCTL-31) (fig. 1)

Cerámica: Toconao Oriente, t.: sin número, urna gris oscura sin pulir, ext. 5YR4/1, altura $60 \mathrm{~cm}$.

Selección: Por representatividad, urna funeraria de base cónica, fases 1 a III (Tarragó 1968: 140).

2. 2320 (---, \pm 170$) 340$ a.C.muestra 21 (UCTL-33) (Le Paige, 1973, fig. 17)

Cerámica: Toconao Oriente, t.: sin número, urna roja pulida, ext. 2.5YR4/4, altura $40,5 \mathrm{~cm}$.

Selección: Por actualización (no clasificada por Tarragó por tratarse de un hallazgo posterior a 1964).

3. $2150(--, \pm 180) \quad 170$ a.C.

muestra 03 (UCTL-19) (fig. 2)

Cerámica: Toconao Oriente, t.: 4340, botellón rojo pulido con estrías verticales, ext. $10 \mathrm{R} 5 / 6$, altura $24,5 \mathrm{~cm}$.

Selección: Por control (tumba fechada por C-14 en 580 a.C., Le Paige 1976: 145); y por representatividad (tipo Rojo Pulido, asociación 4, fase II1, Tarragó 1968: 140).

4. $2020(--, \pm 170) 40$ a.C.

muestra 24 (UCTL-15) (fig. 3)

Cerámica: Quitor-5, t.: sin número, botellón rojo pulido con estrías verticales, ext. 10R4/6, altura $30 \mathrm{~cm}$.

Selección: Por representatividad (tipo Rojo Pulido, fases I a III, ibíd.).

5. $1970(--, \pm 170) \quad 10$ d.C. muestra 22 (UCTL-34) (Le Paige 1973, fig. 15)

Cerámica: Toconao Oriente, t.: ¿4331?, cántaro negro bruñido, ext. $5 Y 2.5 / 1.5$ altura $43 \mathrm{~cm}$.

Selección: Por actualización (omitida en clasificación de Tarragó).

6. $1920(--. \pm 200) 60$ d.C.

muestra 17 (UCTL-47)

Cerámica: Tulor-1, sector D (ext.), fragmento de botellón negro pulido, superficie craquelada, ext. 10YR2.5/1, altura $4 \mathrm{~cm}$.

Selección: Por estratigrafía (encontrada debajo del "horizonte de ocupación superior", Llagostera et al. Ms.).

7. $1900(--., \pm 200) \quad 80$ d.C.

muestra 26 (UCTL-36) (fig. 4)

Cerámica: Toconao Oriente, t.: 4262, vaso rojo bruñido, ext. 10R4/6, altura $13,2 \mathrm{~cm}$.

Selección: Por representatividad ("alfarería rojo-naranja bruñida", asociación 3, fase III, Tarragó 1968: 130 y 1976: 53). 
Observación:

contradicción entre cerámicas del Museo con este número de tumba y contexto según Le Paige (Ms.: 8).

8. $1890(---, \pm 200) 90$ d.C.

muestra 04 (UCTL-30) (fig. 5)

Cerámica: Toconao Oriente, t.: 4731 , botellón rojo pulido con estrías verticales, ext. 5 YR5/4, altura $23,8 \mathrm{~cm}$.

Selección: Por representatividad (tipo Rojo Pulido, asociación 4, fase IIl, Tarragó 1968: 130 y 140, 1976: 50-53).

9. $1860(--, \pm 140) 120$ d.C.

muestra 11 (UCTL-40) (fig. 6)

Cerámica: Toconao Oriente, t.: 4646-8, cántaro gris pulido revestido con polvos rojos, ext. 10YR3/1 y 5 YR5/6, altura $26,6 \mathrm{~cm}$.

Selección: Por estratigrafía (tumba situada debajo de tumba 4645, Le Paige Ms.: 49); y por actualización (cerámica no contemplada en estudios de Tarragó).

10. $1840(-\cdots, \pm 150) \quad 140$ d.C.

muestra 10 (UCTL-39) (fig. 7)

Cerámica: Toconao Oriente, t.: 4645, escudilla gris oscura pulida, ext./int. $10 \mathrm{YR} 3 / 1$, altura $12 \mathrm{~cm}$.

Selección: Por estratigrafía (tumba situada encima de tumba 4646-8, Le Paige ms.: 48); y por representatividad (tipo Negro Pulido, forma 1II, asociación 5, fase III, Tarragó 1968: 130 y 140, 1976: 43).

11. $1830(---, \pm 115) 150$ d.C.

muestra 41 (UCTL-23) (fig. 8)

Cerámica: Toconao Oriente, t.: 4240, botellón gris oscuro pulido con estrías verticales, ext. $5 Y 3.5 / 1$, altura $29 \mathrm{~cm}$.

Selección: Por actualización (omitida en clasificación de Tarragó); y por representatividad (tipo Rojo Pulido asociado a tipo Negro Pulido, forma IIl, asociación 4, fase III, Tarrago 1968: 130 y 140, 1976: 43).

12. $1820(--, \pm 180) 160$ d.C.

muestra 25 (UCTL-35) (fig. 9)

Cerámica: Toconao Oriente, t.: sin número, botellón gris pulido, ext. 10YR3.5/2, altura $37 \mathrm{~cm}$.

Selección: Por representatividad (tipo Negro Pulido, variedad con base cónica de la forma X, decoración A, fase III, Tarragó 1968: 130 y $140,1976: 47)$.

13. 1760 (---, \pm 130$) 220$ d.C.

muestra 43 (UCTL-24)

Cerámica: Toconao Oriente, t.: 4448-9, urna parcialmente rota café rojiza alisada (presenta pequeño recipiente adherido al fondo), ext. $2.5 Y R 4.5 / 4$, altura parcial $21 \mathrm{~cm}$. 


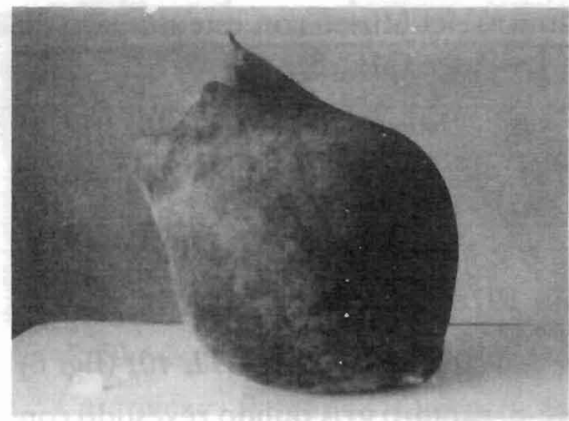

Figura 1: Toconao Oriente, tumba sin número, $2330, \pm 235$ a.p., 350 a.C.

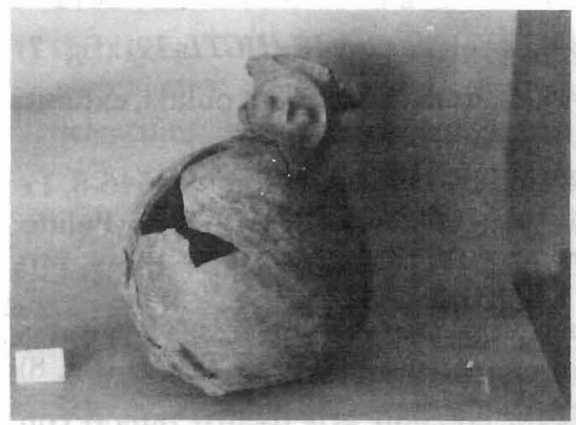

Figura 3: Quitor-5, tumba sin número, 2020 \pm 170 a.p., 40 a.C.

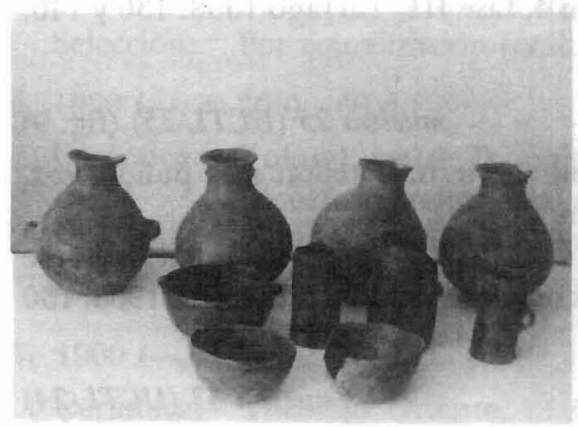

Figura 5: Toconao Oriente, tumba 4731 (hilera sup., extremo der.), $1890 \pm 200$ a.p., 90 d.C.

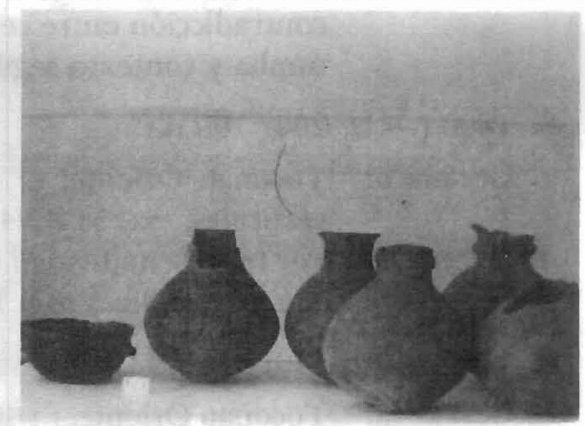

Figura 2: Toconao Oriente, tumba 4340, $2150 \pm 180$ a.p., 170 a.C. ( $2^{\mathrm{a}}$ izq. a der.).

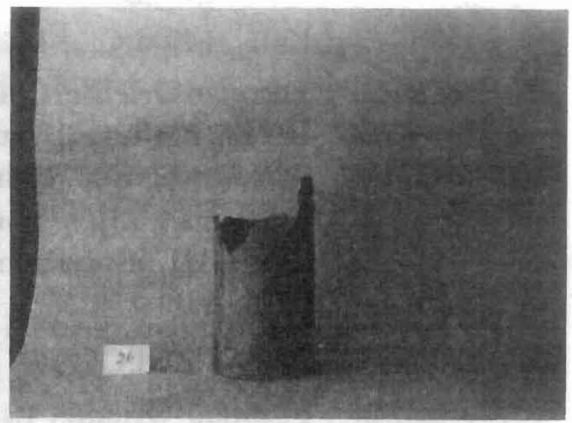

Figura 4: Toconao Oriente, tumba 4262, $1900 \pm 200$ a.p., 80 d.C.

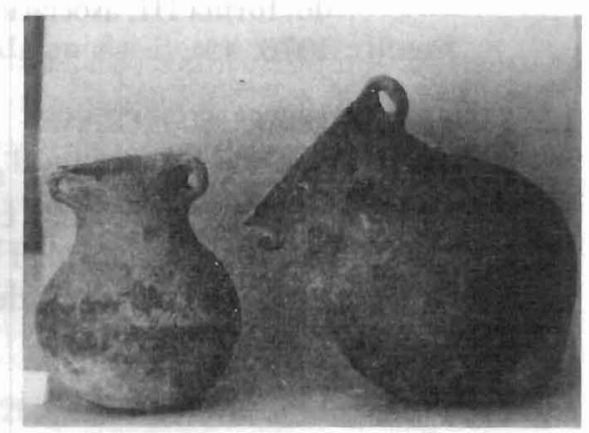

Figura 6: Toconao Oriente, tumba 4646-8 (izq.), $1860 \pm 140$ a.p., 120 d.C. 
Selección: Por actualización (no clasificada por Tarragó por tratarse de un hallazgo posterior a 1964); y por representatividad (tipo Rojo Pulido asociado a tipos Negro Pulido, formas III, IV y VII, asociación 4, fases III a IV, Tarragó 1968: 130 y 140, 1976: 43-44).

14. $1750(---, \pm 160) 230$ d.C. muestra 45 (UCTL-26) (fig. 10)

Cerámica: Toconao Oriente, t.: 4263 , pipa café rojiza suave alisada, ext. 5 YR5.5/4, largo $29,4 \mathrm{~cm}$.

Selección: $\quad$ Por representatividad (tipo Negro Pulido, forma III, asociación 5, fase III, Tarragó 1968: 130 y 140, 1976: 43); y por contexto (la pipa como marcador cronológico, Tarragó 1968, pp. 137-138).

15. $1740(--, \pm 140) 240$ d.C. muestra 40 (UCTL-22)

Cerámica: Toconao Oriente, t.: 4607, escudilla negra pulida con estrías horizontales, ext./int. $2.5 Y 2.5 / 1$, altura $8,8 \mathrm{~cm}$.

Selección: $\quad$ Por representatividad (tipo Negro Pulido, forma III, asociado a tipo Negro Pulido, forma I y a tipo Rojo Pulido, asociación 4, fase III, Tarragó 1968 pp. 130 y I40, 1976, pp. $42-43$ y pp. 50-53).

I6. 1725 (---, \pm 120$) 255$ d.C. muestra 15 (UCTL-32)

Cerámica: Toconao Oriente, t.: 4650 , escudilla gris pulida con estrías, ext./int. $2.5 Y 3 / 0$, altura $8,3 \mathrm{~cm}$.

Selección: $\quad$ Por representatividad (tipo Negro Pulido, forma III, fase III, Tarragó 1968, p. 130 y 140, I976, p. 43).

17. $1670(---, \pm 160) 310$ d.C. muestra 29 (UCTL-21) (fig. 11)

Cerámica: Toconao Oriente, t.: 4383 (bis), botella parcialmente rota negra bruñida, ext. $7.5 Y$ R2.5/0, altura parcial $7,3 \mathrm{~cm}$.

Selección: $\quad$ Por representatividad (tipo Negro Pulido, forma X, decoración $A$ en proceso de esquematización, asociación 5 , fase III, Tarragó 1968, pp. 130 y I40, I968, p. 44 y p. 47); y por contexto (asociada a pipa, collar de turquesa, equipo inhalatorio, Tarragó 1968: 137-139).

18. $1655(---, \pm 190) 325$ d.C. muestra 30 (UCTL-37) (fig. 12)

Cerámica: Toconao Oriente, t.: 4343, cántaro negro pulido, ext. $2.5 Y 2 / 0$, altura $23,5 \mathrm{~cm}$.

Selección: $\quad$ Por actualización (no clasificada por Tarragó por tratarse de un hallazgo posterior a 1964).

Observación: La pertenencia de la escudilla al contexto de esta tumba es 


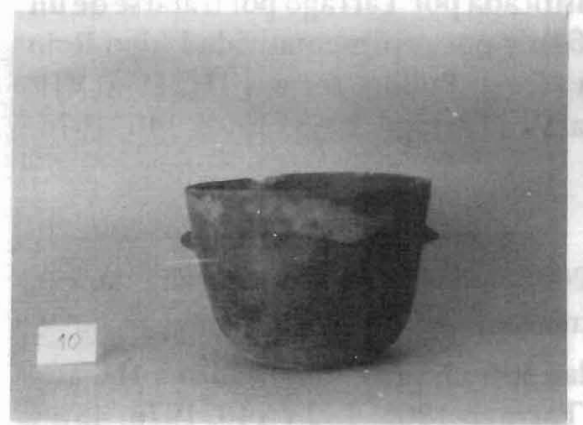

Figura 7: Toconao Oriente, tumba 4645, $1840 \pm 150$ a.p., 140 d.C.

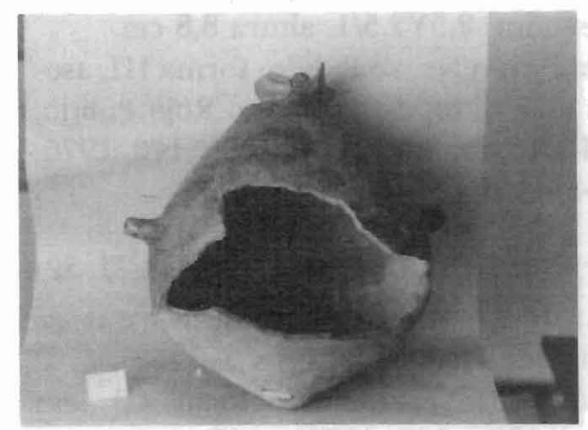

Figura 9: Toconao Oriente, sin número, 1820 \pm 180 a.p., 160 d.C.

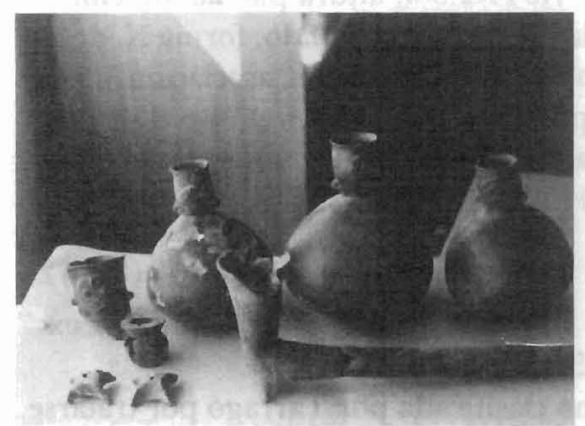

Figura 11: Toconao Oriente, tumba $4383\left(2^{\circ}\right.$ der. a izq.), $1670 \pm 160$ a.p., 310 d.C.

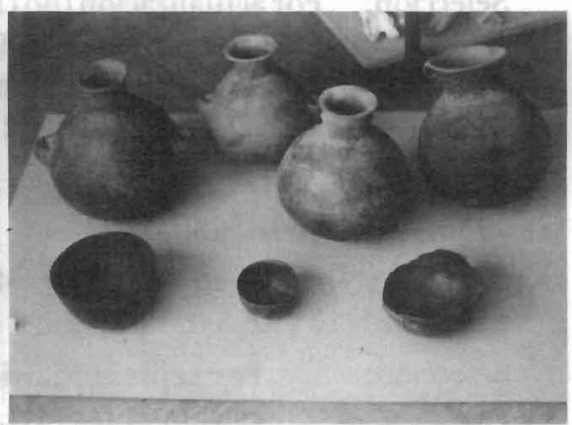

Figura 8: Toconao Oriente, tumba 4240 (hilera sup., extremo izq.), $1830 \pm 115$ a.p., 150 d.C.

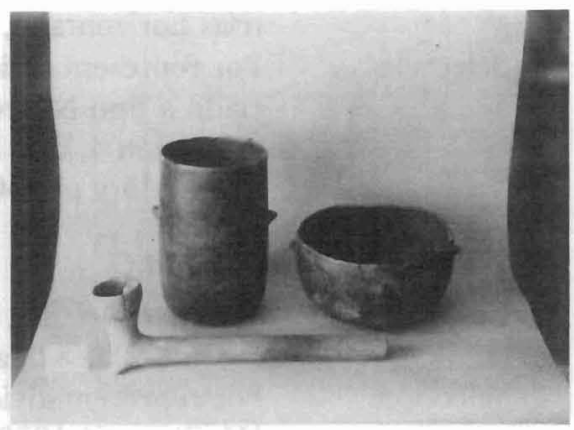

Figura 10: Toconao Oriente, tumba 4263 (hilera sup., der.), $1750 \pm 160$ a.p., 230 d.C.

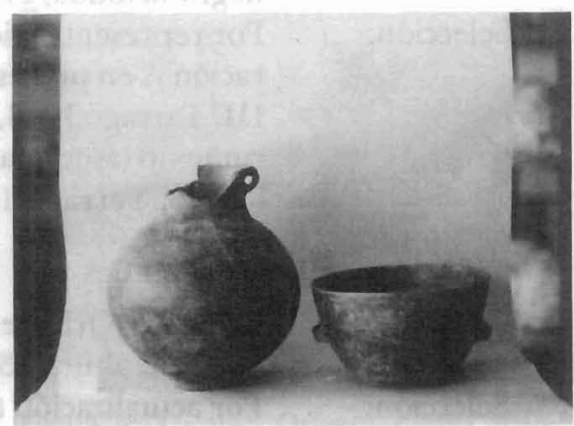

Figura 12: Toconao Oriente, tumba 4343 (izq.), $1655 \pm 190$ a.p., 325 d.C. 
dudosa, ya que hay contradicciones con la relación del contexto según Le Paige (Ms.).

19. $1630(---, \pm 130) \quad 350$ d.C. muestra 44 (UCTL-25)

Cerámica: Toconao Oriente, t.: 4274, botellón café grisáceo oscuro pulido, ext. I0YR3.5/3, altura $22,3 \mathrm{~cm}$.

Selección: $\quad$ Por actualización (no clasificada por Tarragó por tratarse de un hallazgo posterior a 1964).

20. 1540 (---, \pm 100$) \quad 440$ d.C. muestra 01 (UCTL-13) (fig. 13)

Cerámica:

Quitor-5, t.: 3397, escudilla negra pulida con estrías horizontales, ext. 10YR3.5/1, int. 10YR2.5/1, altura $10,6 \mathrm{~cm}$.

Selección: $\quad$ Por control (tumba fechada por C-14 en $1750 \pm 80,200$ d.C., Serraccino 1974a: 107 y Núñez 1976, p. 107).

21. $1470(--, \pm 150) \quad 510$ d.C. muestra 51 (UCTL-49) (fig. 14)

Cerámica: Solcor-3, t.: 12 , pieza $\mathrm{N}^{\circ} 1241$, vasija gris oscura pulida, ext. 2.5Y2.5/0, altura $13,8 \mathrm{~cm}$.

Selección: $\quad$ Por representatividad (tipo Gris Grueso Pulido, forma similar a VII del Negro Pulido, asociación 11 , fase V, Tarragó 1968: 132 y 141, Tarragó 1976: 60); por control (hay dos muestras de madera en proceso para fechado por C-14); y por contexto (hay cestería coiled polícroma y tableta de mango plano en abanico de estilo Tiwanaku, Tarragó 1968: 134 y 139).

Observación: El cuenco con líneas quebradas negras sobre fondo rojo es de filiación desconocida.

22. $1420( --- \pm 145) 560$ d.C. muestra 54 (UCTL-52) (fig. 15)

Cerámica: Solcor-3, t.: 67 , pieza $\mathrm{N}^{\circ} 2434$, escudilla gris oscura pulida, con estrías, ext./int. $2.5 Y 2.5 / 0$, altura $8,5 \mathrm{~cm}$.

Selección: $\quad$ Por representatividad (tipo Negro Pulido, forma III alta, asociación 5, fase III, Tarragó 1968, p. 130 y p. 140, 1976, p. 43); por control (hay dos muestras en proceso para fechado por C-14); y por contexto (hay capachos, cestería coiled polícroma, Tarragó 1968: 139).

Observación: La vasija biesferoide intrusiva es de filiación desconocida y procede probablemente de Tarija (Arellano, comunicación personal 1983).

23. 1400 (---, \pm 140$) 580$ d.C. muestra 39 (UCTL-16)

Cerámica: Quitor-6, t.: 2881, escudilla roja oscura grabada y pulida, ext. $10 \mathrm{R} 3.5 / 6$, altura $10 \mathrm{~cm}$. 


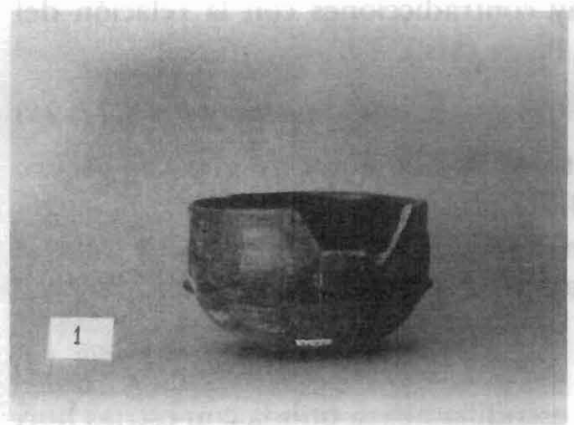

Figura 13: Quitor-5, tumba 3397, $1540 \pm 100$ a.p., 440 d.C.

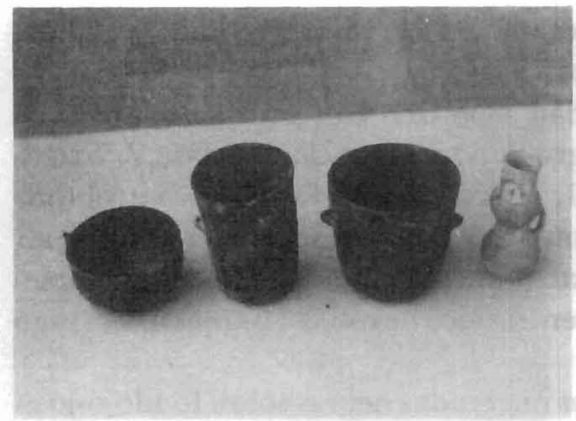

Figura 15: Solcor-3, tumba 67, pieza $\mathrm{N}^{\circ} 2434$ (izq.), $1420 \pm 145$ a.p., 560 d.C.

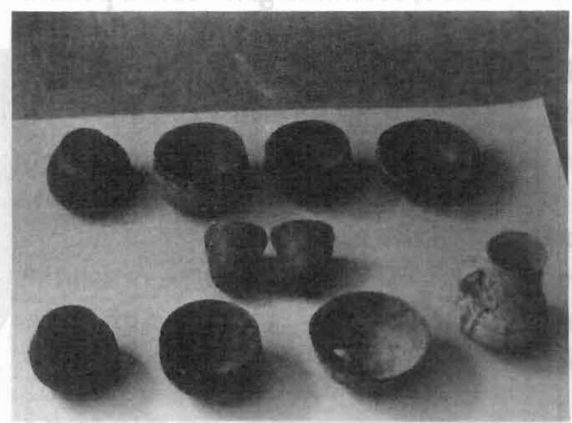

Figura 17: Toconao Oriente, tumbà 4534 (hilera inf., extremo izq.), $1360 \pm 100$ a.p., 620 d.C.

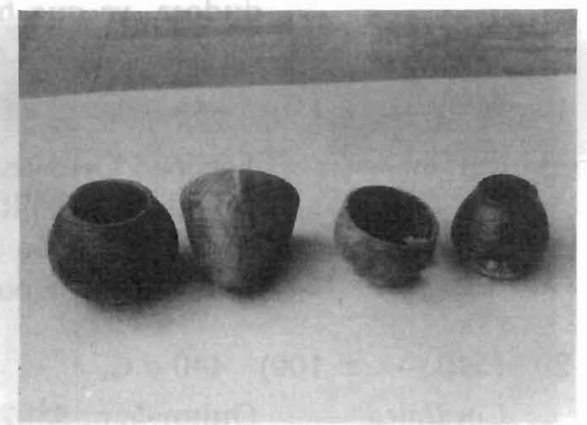

Figura 14: Solcor-3, tumba 12, pieza $\mathrm{N}^{\circ} 1241$ (izq.), $1470 \pm 150$ a.p., 510 d.C.

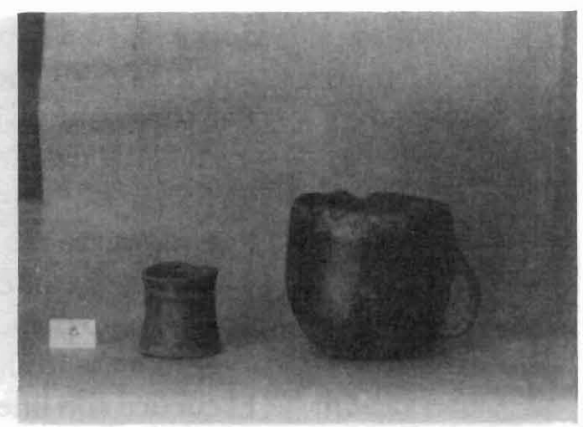

Figura 16: Quitor-5, tumba 2172 (der.), 1400 \pm 140 a.p., 580 d.C.

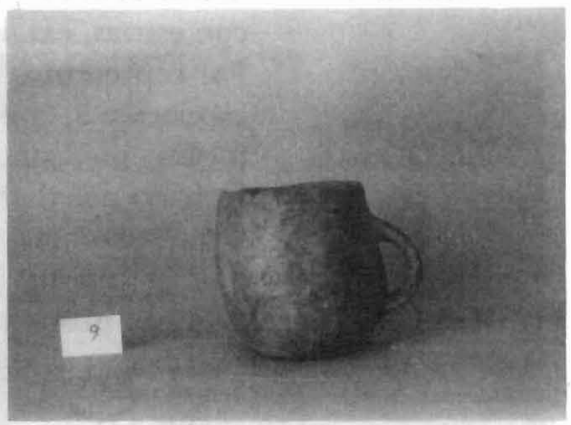

Figura 18: Quitor-5, tumba 2245, $1270 \pm 110$ a.p., 710 d.C. 
Selección: $\quad$ Por representatividad (tipo Rojo Grabado, fases IV y V, Tarragó 1968, p. 132 y p. 141, 1976, pp. 57-59).

Observación: Relación del contex to no ubicable en apuntes de campo de Le Paige.

24. $1400(---, \pm 100) 580$ d.C. muestra 08 (UCTL-28) (fig. 16)

Cerámica:

Quitor-5, t.: 2172, tazón café bruñido, ext. 10YR3/1, altura $13,3 \mathrm{~cm}$.

Selección: $\quad$ Por contexto (asociada a kero Tiwanaku roto en la parte superior, Tarragó 1968: 133-136); y por representatividad (tipo Gris Grueso Pulido, asociación 11, fase V, Tarragó 1968: 132 y 141, 1976: 60).

25. $1360(--, \pm 100) 620$ d.C. muestra 14 (UCTL-20) (fig. 17)

Cerámica: Toconao Oriente, t.: 4534, vasija negra bruñida, ext. $2.5 \mathrm{Y} 2.5 / 0$, altura $10,8 \mathrm{~cm}$.

Selección: $\quad$ Por representatividad (tipo Negro Pulido, forma VII, asociación 6, fase IV, Tarragó 1968, p. 131 y pp. 140-141, 1976 , p. 44).

Observación: Los vasos comunicantes grabados, y la escudilla y el jarro con decoración negro y rojo sobre blanco, son intrusivos y de filiación desconocida, aunque estos últimos podrían proceder de Tarija (Arellano, Ídem).

26. $1320(--, \pm 130) 660$ d.C.

muestra 47 (UCTL-27)

Cerámica: Toconao Oriente, t.: 4432, vasija negra bruñida, ext. $2.5 \mathrm{Y} 2.5 / 0$, altura $8,4 \mathrm{~cm}$.

Selección: $\quad$ Por representatividad (tipo Negro Pulido, forma VII, fase IV, Tarragó 1968, p. 131 y pp. 140-141, 1976, p. 44).

27. $1290(---, \pm 150) 690$ d.C.

muestra 33 (UCTL-38)

Cerámica: Toconao Oriente, t.: 4182, vasija parcialmente rota roja pulida, ext. $2.5 \mathrm{YR} 4 / 6$, altura parcial $14 \mathrm{~cm}$.

Selección: $\quad$ Por actualización (no clasificada por Tarragó por tratarse de un hallazgo posterior a 1964).

Observación: Relación del contexto no ubicable en apuntes de campo de Le Paige.

28. $1270(\cdots, \pm 110) 710$ d.C.

muestra 09 (UCTL-14) (fig. 18)

Cerámica: Quitor-5, t.: 2245, tazón café rojizo suave pulido con estrías verticales, ext. 5 YR5.5/4, altura $10,2 \mathrm{~cm}$.

Selección: Por contexto (asociada a kero Tiwanaku "expansivo", Tarragó 1968: 135); y por representatividad (tipo Gris Grue- 
so Pulido, asociación 11, fase V, Tarragó 1968: 132 y 141, 1976: 60).

29. $1260(\ldots, \pm 95) 720$ d.C.

muestra 53 (UCTL-51) (fig. 19)

Cerámica:

Solcor-3, t.: 50 , pieza $\mathrm{N}^{\circ} 1936$, vaso negro bruñido, ext./int. $2.5 Y 2 / 0$, altura $17,5 \mathrm{~cm}$.

Selección: $\quad$ Por representatividad (tipo Negro Pulido, forma II, asociaciones 7 y 8, fases $1 \mathrm{~V}$ a V, Tarragó 1968: 132 y 140-141, 1976: 42); por control (hay dos muestras en proceso para fechado por C-14); y por contexto (hay hacha de metal, cuentas de collar de mineral de cobre y cestería coiled polícroma, Tarragó 1968: 139).

30. 1260 (---, \pm 130$) 720$ d.C.

muestra 28 (UCTL-29) (fig. 20)

Cerámica:

Quitor-5, t.: sin número, botella gris pulida, ext. 2.5Y2.5/0, altura $16 \mathrm{~cm}$.

Selección: Por representatividad (tipo Gris Grueso Pulido. fase V, Tarragó 1968: 132 y 141, 1976: 60).

31. 1240 (---, \pm 100$) 740$ d.C. muestra 37 (UCTL-46) (Le Paige 1964: 248) Cerámica:

Solor-4, t.: sin número, urna rojo suave sin pulir, ext. 2.5 YR5/2, altura $90 \mathrm{~cm}$.

Selección: $\quad$ Por actualización (omitida en clasificación de Tarragó).

32. 1130 (---, \pm 110$) 850$ d.C. muestra 52 (UCTL-50) (fig. 21)

Cerámica: Solcor-3, t.: 41 , pieza $\mathrm{N}^{\circ} 1825$, escudilla ext. café rojiza alisada, int. café gris oscura pulida, ext. 5YR5.5/3, int. 10YR3/2, altura $6,5 \mathrm{~cm}$.

Selección: $\quad$ Por representatividad (tipo Dupont, Núñez 1965, variedad Ayquina, Orellana 1968, asociación 12, fase V11, Tarragó 1968: 133 y 141 ; 1976: 60); y por contexto (asociada a kero Tiwanaku, Tarragó 1968, p. 135).

33. 1060 (--, \pm 120$) 920$ d.C. muestra 49 (UCTL-48) (fig. 22).

Cerámica: $\quad$ Solcor-3, t.: 05 , pieza $\mathrm{N}^{\circ} 1069$, escudilla gris pulida, ext. altura $12,2 \mathrm{~cm}$.

Selección: $\quad$ Por representatividad (tipo Gris Grueso Pulido, asociación 11, fase V, Tarragó 1968: 132 y 141, 1976: 60); por actualización (asociación a cuenco mitad negro mitad rojo no clasificado por Tarragó por tratarse de un hallazgo posterior a 1964); por control (hay dos muestras de madera en proceso para fechado por C-14); y por contexto (asociada a cestería coiled polícroma y tableta de mango plano en abanico de estilo Tiwanaku, Tarragó 1968, pp. 133-136). 
Observación: El cuenco mitad negro mitad rojo es de filiación desconocida; se han encontrado más ejemplares en Taltal (Núñez, comunicación personal, 1985).

34. $1060(\cdots, \pm 90) 920$ d.C. muestra 34 (UCTL-43) (fig. 23)

Cerámica:

Solor-4, t.: sin número, fragmento de vasija roja oscura

Selección: $\quad$ Por representatividad (tipo Concho de Vino, Rojo Violápulida con estrías horizontales, ext. $7.5 \mathrm{R} 3.5 / 8,5 \times 5 \mathrm{~cm}$. ceo o Rojo Pintado, fase VII, Tarragó 1968: 133 y 141, 1976: 60-61).

35. $1050(---, \pm 70) 930$ d.C. muestra 36 (UCTL-45) (fig. 24)

Cerámica: $\quad$ Solor- 4 , t.: sin número, cántaro rojo oscuro sin pulir, ext. $10 \mathrm{R} 4 / 5$, altura $20 \mathrm{~cm}$.

Selección: $\quad$ Por representatividad (tipo Concho de Vino, Rojo Violáceo o Rojo Pintado, fase VII, Tarragó 1968: 133 y 141, 1976: 60-61).

36. $1040(-\cdot, \pm 130) 940$ d.C. muestra 59 (UCTL-18) (fig. 25)

Cerámica:

Quitor-6, t.: 54, pieza $\mathrm{N}^{\circ} 688$, escudilla ext. café rojiza alisada, int. gris oscura pulida, ext. 5YR4.5/3, int. 5 YR3/1, altura $6,3 \mathrm{~cm}$.

Selección: $\quad$ Por representatividad (tipo Dupont, Núñez 1965, variedad Ayquina, Orellana 1968, asociación con tipo Gris Grueso Pulido no contemplada por Tarragó, fases V y VII, Tarragó 1968: 133 y 141, 1976: 60).

37. $960(--, \pm 75) 1020$ d.C. muestra 12 (UCTL-41) (fig. 26)

Cerámica: Conde Duque Norte, t.: 1600, recipiente gris pulido con estrías, ext. $5 Y 2.5 / 1$, altura $3,3 \mathrm{~cm}$.

Selección: $\quad$ Por representatividad (no clasificada por Tarragó, pero pertenece a tumba de la fase VI, Tarragó 1968: 133 y 141).

38. $840(--, \pm 70) 1140$ d.C.

muestra 58 (UCTL-17)

Cerámica:

Quitor-6, t.: 35 , pieza $N^{\circ} 409$, escudilla ext. café gris oscura alisada, int. café gris oscura pulida, ext./int. $10 \mathrm{YR} 3 / 2$, altura $4,5 \mathrm{~cm}$.

Selección: $\quad$ Por representatividad (tipo Dupont, Núñez 1965, variedad Ayquina, Orellana 1968, asociación 12, fase VII, Tarragó 1968: 133 y 141, 1976: 60); y por contexto (asociada a collar con cuentas de liparita, Tarragó 1968: 139).

Observación: Recientemente se obtuvo fecha C-14 de $710 \pm 70$ a.p., 1240 d.C. 


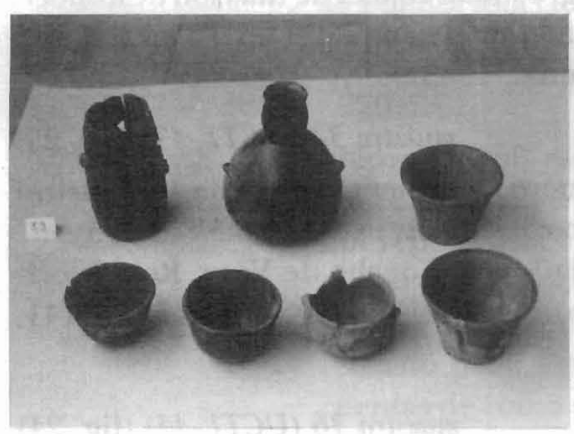

Figura 19: Solcor-3, tumba 50, pieza $\mathrm{N}^{\circ} 1936$ (hilera sup., extremo izq.), $1260 \pm 95$ a.p., 720 d.C.

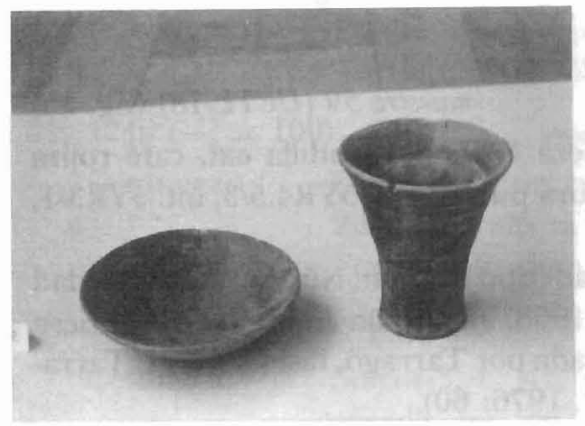

Figura 21: Solcor-3, tumba 41, pieza $\mathrm{N}^{\circ} 1825$ (izq.), $1130 \pm 110$ a.p., 850 d.C.

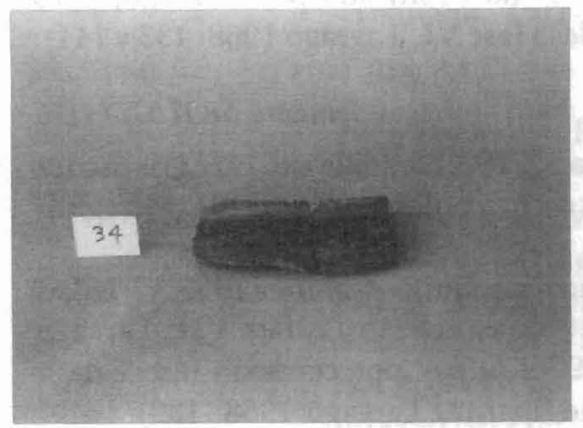

Figura 23: Solor-4, tumba sin número, 1060 \pm 90 a.p., 920 d.C.

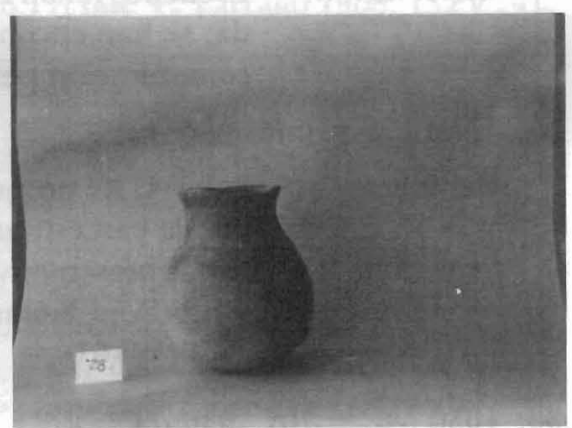

Figura 20: Quitor-5, tumba sin número, 1260 \pm 130 a.p., 720 d.C.

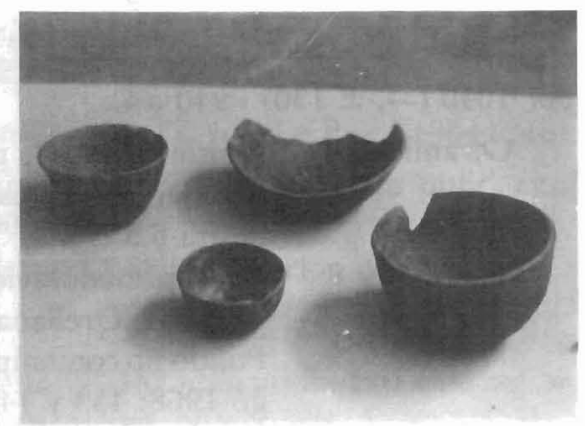

Figura 22: Solcor-3, tumba 05, pieza $\mathrm{N}^{\circ} 1069$ (izq.), $1060 \pm 120$ a.p., 920 d.C.

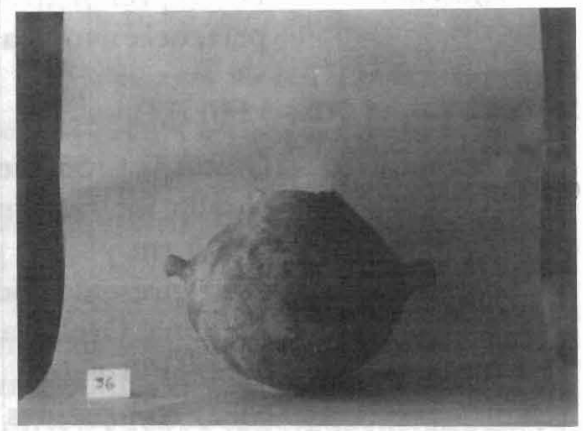

Figura 24: Solor-4, tumba sin número, 1050 \pm 70 a.p., 930 d.C. 


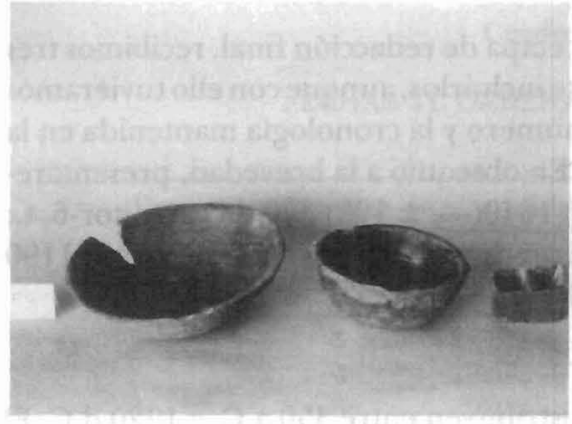

Figura 25: Quitor-6, tumba 54, pieza $\mathrm{N}^{\circ} 688$ (izq.), $1040 \pm 130$ a.p., 940 d.C.

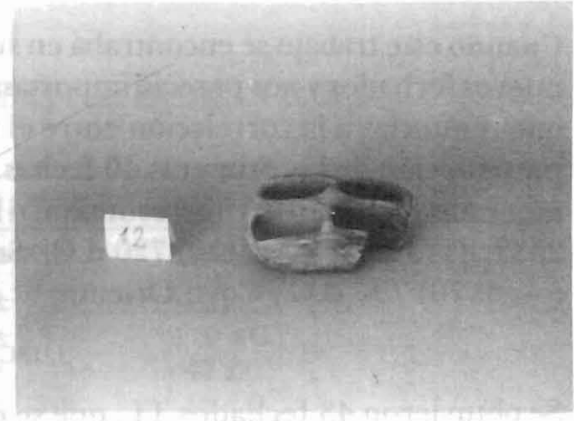

Figura 26: Conde Duque Norte, tumba 1600 , $960 \pm 75$ a.p., 1020 d.C.

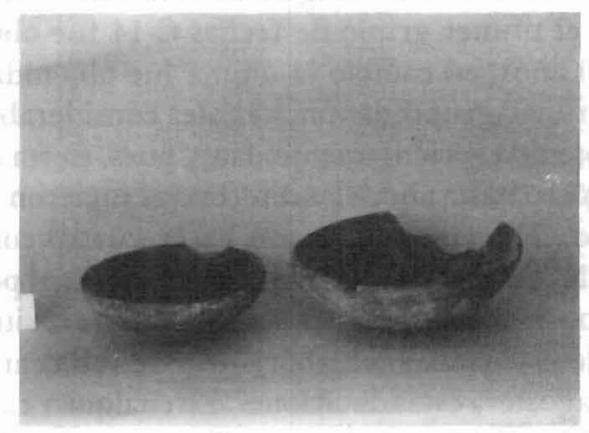

Figura 27: Catarpe, tumba 1855 (izq.), $795 \pm$ 70 a.p., 1185 d.C.

39. $795(---, \pm 70) \quad 1185$ d.C.

muestra 13 (UCTL-42) (fig. 27)

Cerámica:

Catarpe, t.: 1855 , escudilla ext. café rojiza alisada, int. negra pulida, ext. 5YR5/3, int. 7.5R2.75/0, altura $6 \mathrm{~cm}$.

Selección: $\quad$ Por representatividad (tipo Dupont, Núñez 1965, variedad Ayquina, Orellana 1968, asociación 12, fase VII, Tarragó 1968: 133 y $141,1976: 60$ ).

40. $760(--, \pm 70) \quad 1220$ d.C.

muestra 35 (UCTL-44)

Cerámica: Solor-4, t.: sin número, cuenco rojo oscuro pulido, con estrías horizontales, ext. 10R4/6, altura $13 \mathrm{~cm}$.

Selección: $\quad$ Por representatividad (tipo Concho de Vino, Rojo Violáceo o Rojo Pintado, fase VII, Tarragó 1968: 133 y 141, 1976: 60-61). 
Cuando este trabajo se encontraba en su etapa de redacción final, recibimos tres nuevos fechados y nos pareció importante incluirlos, aunque con ello tuviéramos que renunciar a la correlación entre el número y la cronología mantenida en la presentación de las primeras 40 fechas. En obsequio a la brevedad, presentaremos estas fechas en forma resumida: 41 ) $1640(---, \pm 125) 340$ d.C., Quitor-6, t.: 2532 ; 42) $1260\left(-.- \pm\right.$, 120) 720 d.C., Solcor-3, t.: 11 , pieza $N^{\circ} 1213$; y 43) 1190 $(---, \pm 70) 790$ d.C., Coyo Oriente, t.: 4060.

\section{Discusión}

Se obtuvieron 43 fechados TL, que se distribuyen entre 350 a.C. y 1220 d.C. El error del orden del $10 \%$ en las fechas se estima aceptable, tanto desde el punto de vista arqueológico como físico.

En cuanto a los controles radiocarbónicos que habíamos previsto, cabe señalar lo siguiente: 1) tres fechas $T L\left(N^{\circ} 1,20\right.$ y 41$)$ resultaron, respectivamente, un 15,13 y $3,5 \%$ más recientes que las fechas $C-14$ para las mismas tumbas; $y$ 2) otra ( $\mathrm{N}^{\circ} 38$ ) resultó un $18 \%$ más antigua. Las diferencias más evidentes entre ambos casos, es que el primer grupo de fechas C-14 fue obtenido hace más o menos entre 10 y 20 años, en cambio la última fue obtenida hace unos pocos meses; además, el primer grupo data materiales considerablemente más antiguos que la fecha obtenida recientemente. Hay, pues, cierta consistencia en los resultados dispares, pero hasta ahora las diferencias sugieren únicamente correlación, no causalidad. Teníamos planeado hacer cuatro controles más sobre tumbas de Solcor-3 ( $\mathrm{N}^{\circ} 21,22,29$ y 33) correspondientes al periodo intermedio entre ambos casos, con lo cual talvez habríamos aclarado la situación. Desgraciadamente, al cierre de este trabajo el laboratorio de radiocarbón aún no había enviado a Agustín Llagostera estas dataciones. En cualquier caso, la contemporaneidad entre fechas TL y C-14 para cerámica Dupont en San Pedro de Atacama, y fechas TL y C-14 para la misma cerámica en el Loa Superior (véase discusión de la fase VII), es una evidencia independiente que hay que tomar en cuenta al momento de evaluar este programa de datación.

En la discusión que sigue, se contrastan los resultados presentados en la sección anterior con la secuencia general propuesta por Tarragó (1968: 140141). Aunque la autora no fue precisa en los rangos cronologicos que corresponden a cada una de las ocho fases, éstos pueden deducirse de la columna de fechas que colocó a la izquierda de la secuencia. En el análisis de cada fase, se discuten en primer lugar los resultados a partir de las cerámicas o asociaciones cerámicas que la propia autora considera representativas. Luego, bajo el acápite de "comentarios", se reordenan dichos resultados conforme a nuestra interpretación, incorporando, cuando es pertinente, los nuevos hallazgos, datos omitidos por la investigadora y otras observaciones que nos parecen importante (un resumen de las fechas, de acuerdo a estas interpretaciones, se halla en el Cuadro 2).

De este análisis crítico surge una nueva cronología y una secuencia actualizada, cuyos lineamientos principales hemos sintetizado en el Cuadro 3 
Cuadro 2

FECHAS TL ORDENADAS POR FASES

\begin{tabular}{|c|c|c|c|}
\hline Fase & Número & Edad & Fecha \\
\hline I & 1 & $2330(--, \pm 235)$ & 350 a.C. \\
\hline II & $\begin{array}{l}2^{*} \\
3 \\
4 \\
5^{*} \\
6 \\
7 \\
8 \\
9^{*}\end{array}$ & $\begin{array}{l}2320(--, \pm 170) \\
2150(--, \pm 180) \\
2020(--, \pm 170) \\
1970(--, \pm 170) \\
1920(--, \pm 200) \\
1900(--, \pm 200) \\
1890(--, \pm 200) \\
1860(--, \pm 140)\end{array}$ & $\begin{array}{l}340 \text { a.C. } \\
170 \text { a.C. } \\
40 \text { a.C. } \\
10 \text { d.C. } \\
60 \text { d.C. } \\
80 \text { d.C. } \\
90 \text { d.C. } \\
\text { I20 d.C. }(-)\end{array}$ \\
\hline 111 & $\begin{array}{l}10 \\
11 \\
12 \\
13 \\
14 \\
15 \\
16 \\
17 \\
18^{*} \\
41 \\
19^{*}\end{array}$ & $\begin{array}{l}1840(--, \pm 150) \\
1830(--, \pm 115) \\
1820(--, \pm 180) \\
1760(--, \pm 130) \\
1750(--, \pm 160) \\
1740(--, \pm 140) \\
1725(--, \pm 120) \\
1670(--, \pm 160) \\
1655(--, \pm 190) \\
1640(--, \pm 125) \\
1630(--, \pm 130)\end{array}$ & $\begin{array}{l}140 \text { d.C. } \\
150 \text { d.C. } \\
160 \text { d.C. } \\
220 \text { d.C. } \\
230 \text { d.C. } \\
240 \text { d.C. } \\
255 \text { d.C. } \\
310 \text { d.C. } \\
325 \text { d.C. } \\
340 \text { d.C. }(+) \\
350 \text { d.C. }\end{array}$ \\
\hline $1 \mathrm{~V}$ & $\begin{array}{l}20 \\
21 \\
22 \\
23 \\
24 \\
25 \\
26 \\
27^{*} \\
29 \\
42\end{array}$ & $\begin{array}{l}1540(--, \pm 100) \\
1470(--, \pm 150) \\
1420(--, \pm 145) \\
1400(--, \pm 140) \\
1400(--, \pm 100) \\
1360(--, \pm 100) \\
1320(--, \pm 130) \\
1290(--, \pm 150) \\
1260(--, \pm 95) \\
1260(--, \pm 120)\end{array}$ & $\begin{array}{l}440 \text { d.C. } \\
510 \text { d.C. } \\
560 \text { d.C. }(-) \\
580 \text { d.C. } \\
580 \text { d.C. } \\
620 \text { d.C. } \\
660 \text { d.C. } \\
690 \text { d.C. } \\
720 \text { d.C. } \\
720 \text { d.C. }(-)\end{array}$ \\
\hline $\mathbf{v}$ & $\begin{array}{l}28 \\
30 \\
31^{*} \\
43 \\
32 \\
34 \\
33 \\
35 \\
36\end{array}$ & $\begin{array}{l}1270(--, \pm 110) \\
1260(--, \pm 130) \\
1240(--, \pm 100) \\
1190(--, \pm 70) \\
1130(--, \pm 110) \\
1060(--, \pm 90) \\
1060(--, \pm 120) \\
1050(--, \pm 70) \\
1040(--, \pm 130)\end{array}$ & $\begin{array}{l}710 \text { d.C. } \\
720 \text { d.C. } \\
740 \text { d.C. }(+) \\
790 \text { d.C. } \\
850 \text { d.C. } \\
920 \text { d.C. } \\
920 \text { d.C. } \\
930 \text { d.C. } \\
940 \text { d.C. }\end{array}$ \\
\hline VI & - & - & - \\
\hline VII & $\begin{array}{l}37^{*} \\
38\end{array}$ & $\begin{array}{l}960(--, \pm 75) \\
840(-\cdots, \pm 70)\end{array}$ & $\begin{array}{l}1020 \text { d.C. } \\
1140 \text { d.C. }\end{array}$ \\
\hline
\end{tabular}




\begin{tabular}{lccc}
\hline Fase & Número & Edad & Fecha \\
\hline & 39 & $795(--, \pm 70)$ & 1185 d.C. \\
& 40 & $760(--, \pm 70)$ & 1220 d.C. \\
VIII & \multicolumn{3}{c}{ no fue testeada }
\end{tabular}

* Por actualización. (-) Podría ser más temprana. (+) Podría ser más tardía.

\section{Fase I}

La referencia de la autora a una "cerámica ordinaria" perteneciente a esta fase es, por desgracia, muy vaga, por lo que no fue posible identificar piezas para datación. En cuanto a las "urnas de base cónica" (cf. Le PAIGE, 1964: Lám. 144, figs. 1 y 2 ), se fechó un solo ejemplar $\left(\mathrm{N}^{\circ} 1\right)$, resultando 650 años más temprano que la fecha dada por Tarragó para el término de esta fase.

Comentarios. De acuerdo al test por TL, esta casi legendaria fase con urnas - presente en la base de todas las secuencias a partir de 1962, pero nunca caracterizada con detalle- podría tener cierto sustento. Al menos, proporciona la más antigua de las fechas TL. Sin embargo, recomendamos mantenerla como hipotética, ya que todavía no hay suficientes evidencias para caracterizarla (cf. TARRAGó ibíd.: 140) y, por lo demás, es riesgoso sustentarla sobre la base de una sola fecha. En todo caso, esta fecha no está aislada en el ámbito regional. Las fechas de Tulán Cueva (Núñez, 1976: 108), Chiuchiu 200 (Benavente Ms.) y Alero Toconce (Aldunate et al. Ms.), entre 1760 a.C. y 350 a.C., permiten sostener con holgura una antigüedad tal para las tradiciones alfareras tempranas en el salar. Es necesario contextualizar esta fase, hacer nuevas dataciones y explorar las vinculaciones de estas urnas con cerámicas encontradas en la superficie de varios sitios de San Pedro de Atacama y que tradicionalmente han sido evaluadas como las cerámicas más tempranas de la región.

\section{Fase II}

Siguiendo a Tarragó (ibíd: 129, 130 y 140), corresponderían a esta fase "las vasijas de Larrache que carecen de datos de asociaciones de tumbas"; los "vasos rojos bruñidos, cilíndricos, o Rojo Pulido atípico"; "una vasija negra pulida de paredes gruesas, tamaño grande, cuerpo ovoide con base cónica y dos asas verticales cerca del borde"; y las "urnas negras pulidas". Se encontraron piezas similares de todos los grupos, salvo el último $\left(\mathrm{N}^{\circ} 2,5,7\right.$ y 9 , respectivamente).

El rango cronológico postulado por Tarragó para esta fase es 300 d.C. a 400 d.C. y el obtenido a través de las dataciones absolutas 340 a.C. a 120 d.C.

Comentarios. Nuestro rango cronológico estimativo para esta fase es 300 a.C. a 100 d.C. La fecha inicial la hemos hecho algo más reciente de lo que indica la más 


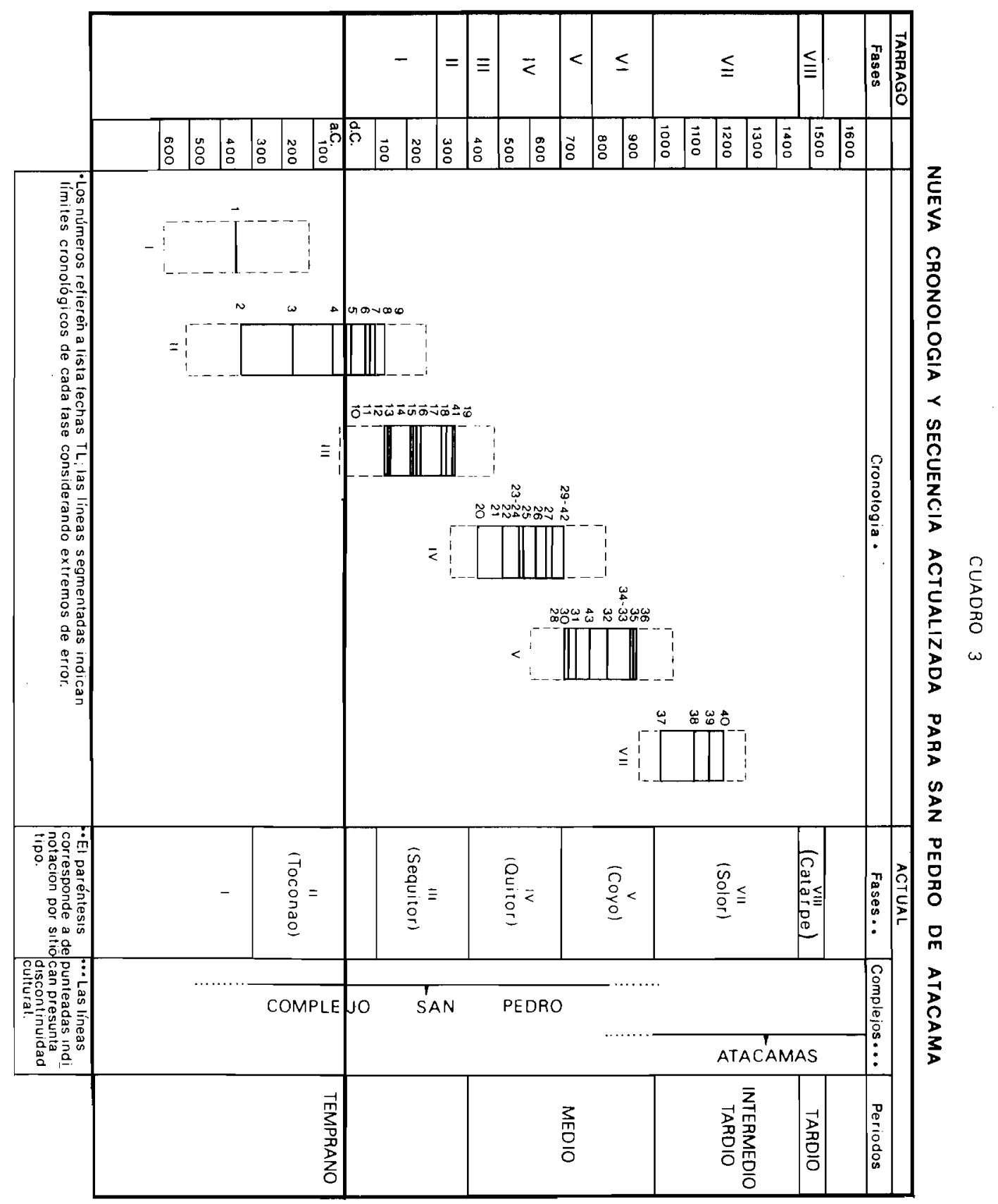


temprana de sus fechas, por su cercanía a la fecha de la urna. La fecha final, en cambio, se basa en los datos de superposición estratigráfica entre las fechas $\mathrm{N}^{\circ} 9$ y 10. En este entendido, entonces, habría que incorporar a esta fase a todas aquellas cerámicas o asociaciones cerámicas fechadas dentro de dicho rango $\left(N^{\circ} 3,4,6\right.$ y 8). Esta reubicación, sin embargo, plantea el primer problema serio con la secuencia de Tarragó, ya que las fechas 3 y 8 corresponden a la asociación 4, atribuida a la fase III. En nuestra opinión, éste dejaría de ser un problema si aceptáramos que -como ocurre en todas las secuencias- en una fase previa ocurren con baja frecuencia muchos de los elementos que van a caracterizar a la siguiente. En cambio, la ubicación en la fase II de la pieza con la fecha 4 no ofrece problema, en la medida que Tarragó (ibid: 129) incluyó "el tipo rojo pulido con una cara antropomorfa aplicada al pastillaje sobre la superficie del cuello" en la asociación 1. En cuanto al gollete de Tulor- $1\left(\mathrm{~N}^{\circ} 6\right)$, éste parece pertenecer a botellones como el de la figura 5 (hilera superior, extremo izquierdo), con dataciones coherentes entre sí.

Tomando en cuenta el contenido de la fase II según Tarragó y los agregados que hemos hecho, la formulación de una fase con cerámica roja pulida sin asociación a la negra pulida (Congreso, 1963; Orellana, 1963, 1964) es hoy, definitivamente, un planteamiento superado.

Un problema especial lo plantea la diferencia entre la fecha $\mathrm{C}-14$ para la tumba 4340 de Toconao Oriente y la fecha TL para la misma tumba $\left(\mathrm{N}^{\circ} 3\right)$, puesto que se encuentran separadas por más de 400 años. Lamentablemente, la fecha de C-14 nunca ha sido publicada con su desviación estándar (LE PAIGE, 1976: 145; NúNEEZ, 1976: 107-108; RIVERA, 1980: 164), de modo que no sabemos si considerando los extremos de error de ambas fechas, éstas pueden superponerse. Por fortuna, disponemos de una segunda muestra para esta tumba, proveniente de otra vasija, por lo que en el futuro quizás podríamos dirimir el asunto.

\section{Fase III}

Tarragó caracteriza a esta fase por las asociaciones 2, 4 y 5 . La primera de estas asociaciones no fue fechada. Las dos últimas, en cambio, están bien datadas por las fechas 11, 13, 15 y 16 (asociación 4) y 14, 17, 18 y 22 (asociación 5). Los elementos cerámicos, así como los atributos de los elementos considerados por Tarragó para caracterizar a esta fase, operan realmente como marcadores cronológicos. Es el caso, por ejemplo, de las formas I, III y IV del Negro Pulido $\left(\mathrm{N}^{\circ} 11,13\right.$ y 15); de la "variedad con base cónica de la forma X" del Negro Pulido $\left(N^{\circ} 11\right.$ y 12); de la "decoración naturalista de la cara antropomorfa sobre el cuello" en la forma X del Negro Pulido o decoración "A" ( $N^{\circ} 11,12$ y 17); de las "pipas de cerámicas grises o rojizas, de superficies pulidas, formas angulares con largo tubo, hornillo troncocónico invertido y dos apéndices cónicos como apoyo" ( $N^{\circ} 14$ y 17); y de las "vasijas alisadas ("urnas") mencionadas en el tipo de 
asociación 2" ( $\left.\mathrm{N}^{\circ} 11\right)$, aunque estas últimas piezas, así como también el Negro Pulido III y los botellones Rojo Pulido con gollete sin decoración, aparecen ya desde la fase anterior.

El rango cronológico postulado por Tarragó para esta fase es 400 d.C. a 500 d.C. y el obtenido a través de las dataciones absolutas 170 d.C. a 560 d.C.

Comentarios. Nuestro rango cronológico estimativo para esta fase es 100 d.C. a 400 d.C. Para la fecha de comienzo valen los mismos argumentos de superposición estratigráfica entre las fechas 9 (fase II) y 10 (fase III). Pero la fecha de 560 d.C. para el término de esta fase nos parece excesiva, sobre todo por lo aislada que está. El contexto de esta fecha $\left(\mathrm{N}^{\circ} 22\right)$ debe ser interpretado no como el exponente final de la fase III, sino como un simple remanente de ella perteneciente a la fase IV.

Este es el lugar para señalar que muchas de las cerámicas de esta fase asimiladas al Negro Pulido, carecen del bruñido característico de este tipo, y sería más propio referirse a ellas como una variante "Gris Fina Pulida". Considerando las diferencias cronológicas entre ambos acabados de superficie, esta distinción es importante.

También es importante comentar que el $\mathrm{N}^{\circ} 17$ (consúltese contexto completo en el Museo), documenta la segunda fecha más temprana para el "complejo alucinógeno" en el salar de Atacama (la más antigua es de 250 d.C., t.: 2532 de Quitor-5); al mismo tiempo, documenta la fecha más reciente para una pipa de cerámica. Al respecto, C.M. Torres (1984: 25) dice que "la asociación de tabletas con pipas es sumamente rara, sucediendo en sólo cuatro ocasiones" (cf. LE PaIGE, 1964: Lám. 121, fig. 1). Con toda probabilidad, entonces, la fecha en cuestión data el momento en que las pipas comienzan a disminuir y las tabletas a aumentar en los ajuares funerarios de la región. Por otra parte, la ausencia de iconografía Tiwanaku en la tableta de esta tumba y su temprana fecha, sugieren que el artefacto mismo se encontraba en uso aquí con anterioridad a las influencias de esa cultura altiplánica. Con respecto al pilón o morterito de madera de esta tumba, ésta es la segunda vez que el tipo botelliforme se encuentra en un . contexto fechado con anterioridad a 400 d.C. (cf. LE PAIGE ibíd.: Lám. 129, fig. 1), circunstancia que podría indicar que esta forma de pilón es anterior a la hiperboloide y a la cilíndrica.

\section{Fase IV}

Tarragó (ibíd.: 131-132) caracteriza a esta fase por las asociaciones 6,7 y 8 ; también señala relaciones con Tiwanaku Clásico. La asociación 6 está datada por las fechas 25,41 y 42 . Las asociaciones 7 y 8 no están datadas como tales.

Los elementos cerámicos, así como los atributos de elementos tomados en cuenta por Tarragó para definir a esta fase, operan efectivamente como marcadores cronológicos. Tal es el caso, por ejemplo, de las formas II, VII y IX del 
Negro Pulido ( $\mathrm{N}^{\circ} 25,26,29,41$ y 42); y de la forma $\mathrm{X}$ del Negro Pulido decoradas "con dos hileras de círculos" o decoración "B" ( $N^{\circ} 29$ y 41). El comportamiento cronológico del tipo Rojo Grabado, por su parte, guarda perfecta relación con los planteamientos de Tarragó ( $\mathrm{N}^{\circ} 23$ y 29). La fecha 29 , sin embargo, data tan sólo un momento tardío del tipo Negro Grabado (obsérvese su asociación con el tipo Gris Grueso Pulido).

El rango cronológico postulado por Tarragó para esta fase es 500 d.C. a 700 d.C. y el obtenido a través de las dataciones absolutas 340 d.C. a 720 d.C.

Comentarios. Nuestro rango cronológico estimativo para esta fase es 400 d.C. a 700 d.C. El contexto de la fecha 41 - datado también por C-14 con una fecha similar - correspondería a las primeras expresiones de la alfarería negra bruñida cuando aún no finaliza la fase III. Los rostros semiestilizados de las botellas fechadas en 310 d.C. $\left(N^{\circ} 17\right)$ parecen ser también expresión de estos primeros atisbos de la fase IV, que comienzan a manifestarse en las postrimerías de la fase III.

En cuanto al tipo Gris Grueso Pulido que, en buena parte, es asimilable a lo que Le Paige denominaba alfarería "casi pulida" (TARragó ibíd.: 132), se haya presente desde muy temprano en la fase IV, haciendo pensar que es más frecuente en las tumbas de la época de lo que Tarragó sugiere (ibíd.: 131; $\mathrm{N}^{\circ} 21$ y 24).

La cerámica de la tumba 3397 de Quitor-5 ( $\mathrm{N}^{\circ} 20$ ), por su parte, plantea algunos problemas. En efecto, tiene una fecha C-14 de $200 \pm 80$ d.C., pero por el color de la pasta y el grueso de sus paredes, similar a la alfarería "casi pulida", debería ser muy posterior. La fecha TL, en cambio, la sitúa en la fase IV, datación que aceptamos (no sin reservas) en función de dos argumentos: 1) es similar a la forma IX del Negro Pulido, típica de esta fase; y 2) el tipo Gris Grueso Pulido, al cual su pasta y paredes se parecen, presenta - como vimos - algunas piezas fechadas en contemporaneidad con dicha fase.

Con respecto a los materiales Tiwanaku asociados a cerámicas fechadas por TL, es importante destacar que la tableta con "mango" plano en abanico, de la tumba 12 de Solcor-3 ( $\left.\mathrm{N}^{\circ} 21\right)$, y sobre todo, el kero de la tumba 2172 de Quitor-5 ( $\mathrm{N}^{\circ} 24$ ), constituyen los registros fechados más tempranos relacionados con esa cultura altiplánica, encontrados hasta ahora en el salar de Atacama. Tales fechas se acercan ostensiblemente a las estimaciones entre 400 y $500 \mathrm{~d}$.C. postuladas por Tarragó (ibid.: 140; 1976: 53; 1977: 52 y 55) para los comienzos de las influencias de Tiwanaku en la región.

\section{Fase V}

Esta es la fase en que según Tarragó la tradición alfarera negra pulida empieza a perder definición. Efectivamente, pese a que la cerámica de esta fase presenta ciertas semejanzas con formas del tipo Negro Pulido, la calidad disminuye notoriamente, sus "superficie no poseen ya el color negro intenso ni el bruñido 
de aquel tipo" y el "espesor de sus paredes aumenta en forma notable" (TARRAGÓ, 1968: 132). La cronología de este evento se encuentra relativamente bien precisada a través de las fechas 28,30 y 33 . La autora define a esta fase por la asociación 11, compuesta de formas como la "taza subcilíndrica con un asa doble adherida vertićal" ( $\mathrm{N}^{\circ} 28$ ), la "escudilla simple hemisférica ( $\mathrm{N}^{\circ} 33$ y 36 ), el "puco subcónico" ( $\left.N^{\circ} 43\right)$, el "vaso ovoide, base sin diferenciar, con una insinuación de inflexión que determina un borde alto sin llegar a ser un cuello por sus proporciones" ( $\left.\mathrm{N}^{\mathrm{o}} 21\right)$, y un "botellón de contorno inflexionado con cuerpo ovoide y cuello hiperboloide" ( $\left.\mathrm{N}^{\circ} 30\right)$.

El rango cronológico postulado por Tarragó para esta fase es 700 d.C. a 800 d.C. y el obtenido a través de las dataciones absolutas 510 d.C. a 940 d.C.

Comentarios. Nuestro rango cronológico estimativo para esta fase es 700 d.C. a $1000 \mathrm{~d}$.C. Tal como lo dijimos en la discusión de la fase $1 \mathrm{~V}$, y como por lo demás lo señala Tarragó (ibíd.: 131), los materiales cerámicos que esta autora atribuye a la fase $\mathrm{V}$, también aparecen en la fase anterior. Nuestra interpretación es que esas cerámicas constituyen únicamente atisbos de la fase $V$ en plena fase IV y deben ser conceptuadas como parte de ésta. El inicio de la fase $V$ está bien datado por la fecha 29, correspondiente a una tumba que contiene los últimos exponentes del tipo Negro Pulido, asociados a cerámica roja grabada, negra grabada y gris gruesa pulida; y el final se encuentra igualmente bien datado por la fecha 36 , correspondiente a una tumba que contiene una escudilla gris gruesa pulida asociada al tipo cerámico tardío conocido como Dupont (variante Ayquina).

Una evidencia independiente que apoya el rango cronológico dado por nosotros a esta fase, es una figurilla de filiación Aguada, encontrada en el cementerio de Coyo Oriente asociada a cerámica "casi pulida" (Berenguer, 1984: 14). La cultura Aguada, del noroeste argentino, se sitúa por dataciones C- 14 entre 650 y 900 d.C.

Respecto a lo dicho por Tarragó (ibíd.: 135) en orden a que "más del 50\%" de los materiales Tiwanaku se asocia en las tumbas a cerámica negra pulida, el reciente estudio de M. Orellana (Ms.) no respalda esta afirmación. Por la naturaleza de nuestro trabajo, no podemos dirimir el asunto, pero tenemos la impresión de que los materiales Tiwanaku pertenecientes a la fase IV de San Pedro no son tantos como dice la autora, ni tan pocos como lo sugiere Orellana. La más frecuente asociación de estos materiales es con cerámica "casi pulida" o gris gruesa pulida (fase V), lo cual estaría dando la razón a Orellana, pero la significativa presencia de esta cerámica en la fase IV, con fechas bastante tempranas (ver supra), presta cierto apoyo a Tarragó, al menos en lo que se refiere a las implicancias cronológicas de dichos materiales. Digamos en favor de Tarragó que las observaciones de Orellana se basan, esencialmente, en las excavaciones de Coyo Oriente, muy posteriores a 1964, y que la autora habia anticipado la posibilidad de que nuevos datos cambiaran su planteamiento (ibíd.: 132). En 
todo caso, las recientes excavaciones en Solcor-3 (Bravo y Llagostera Ms.) no han hecho sino confirmar lo apreciado en Coyo.

Otra observación es que la hipotética segregación que Tarragó (ibíd.: 134135) hace entre un grupo de materiales de Tiwanaku "puro" y otro "transformado", carece, al parecer, de significación cronológica. De hecho, la fecha TL de $580 \pm 100$ d.C. para la tumba 2172 de Quitor-5 ( $\left.N^{\circ} 24\right)$, data un kero que, de acuerdo a los criterios estilísticos que ella maneja es "expansivo" o "decadente" y, por lo tanto, situable en un tiem po tardío dentro del milenio (idem. fecha $\mathrm{N}^{\circ} 28$ ). Lo inverso también ocurre: existe un kero-retrato de madera de la tumba 3236 de Quitor-9 asociado a cerámica Huruquilla, que según el criterio estilístico mencionado sería definido como "puro" o "clásico" y situado cerca de la mitad del milenio, pero tiene una fecha C-14 de $1050 \pm 80 \mathrm{~d}$.C. La verdad es que la interpretación de las diferencias entre una cerámica "clásica" y otra "expansiva" o "decadente", como manifestaciones de distintas fases de la cultura Tiwanaku, tiene cada día menos adeptos (véase por ejemplo Ponce, 1981: 53; también Lumbreras y Mujica, 1982: 7). No es que la cerámica de Tiwanaku sea invariable a través del tiempo, sino que los atributos de variación considerados hasta ahora parecen no tener significación cronológica. En nuestra opinión, estos argumentos son tan válidos para la cerámica Tiwanaku encontrada en San Pedro de Atacama como para los artefactos de madera con iconografía de la cultura altiplánica. En suma: la distinción en San Pedro entre un grupo de artefactos representativos de un momento "clásico" de Tiwanaku y otro de un momento "expansivo" (e incluso "decadente") nos parece forzada.

\section{Fase VI}

Esta es la fase más problemática de la secuencia general propuesta por Tarragó. El principal problema se suscitó al tratar de fecharla. Tarragó (ibíd.: 141) no menciona ninguna asociación específica para esta fase y la referencia a una cerámica "alisada" es demasiado vaga como para identificarla en el Museo. Incluso, la autora dice que la mayoría de los contextos funerarios de la fase Vl no contienen cerámica, tienen asociaciones muy pobres o bien no presentan ajuar alguno. Esta fue una seria limitación, por cuanto los contextos más característicos son los que carecen de cerámica y sin cerámica no hay datación por TL. Para salvar esta situación, se seleccionó un contexto sin vasijas y pobre en asociaciones, pero que contenía un pequeño recipiente ("cajita") de cuatro compartimentos hecho en cerámica ( $\left.N^{\circ} 37\right)$. La datación, aunque única y por lo tanto sujeta a reservas, proporcionó un hito cronológico aceptable.

El rango cronológico postulado por Tarragó para esta fase es 800 d.C. a 1000 d.C. La falta de otra fecha TL no permitió obtener un rango cronológico.

Comentarios. No sabemos en qué medida estos contextos pobres, a veces con cerámica alisada, constituyen realmente una fase propiamente tal o son parte de la siguiente. Este es un problema que sólo futuras investigaciones podrán diluci- 
dar. En la discusión de la fase VII se verá que los tipos Dupont y Rojo Violáceo que la caracterizan, aparecen sin interrupciones desde el 800 d.C. en adelante, cubriendo el lapso que supuestamente corresponde a la fase VI. Hemos considerado la posibilidad de que estas superposiciones sean expresión de una ocupación multiétnica de los oasis, pero los datos son aún insuficientes para formalizar una hipótesis en ese sentido. De ahí que recomendemos por mientras sacar esta fase de la secuencia general. En cuanto a la ubicación en esta fase de piezas intrusivas Isla (ibíd.: 141), los ajustes cronológicos que posteriormente hiciera la autora (TARRAGó, 1977) no son consistentes con la única fecha $T L\left(\mathrm{~N}^{\circ} 37\right)$, ya que menciona asociación de cerámica Isla con elementos de la fase IV de San Pedro.

\section{Fase VII}

Tarragó (1968: 133) caracteriza a esta fase por las asociaciones 12 y 13; también menciona relaciones con Huruquilla-Yura y Tilcara-Yavi. La asociación 12 está datada por las fechas $32,36,38$ y 39 ; y la asociación 13 por las fechas 34,35 y 40 .

El rango cronológico postulado por Tarragó para esta fase es 1000 d.C. a 1470 d.C. y el obtenido por TL 740 d.C. a 1220 d.C.

Comentarios. Nuestro rango cronológico estimativo para esta fase es 1000 d.C. a $1470 \mathrm{~d}$.C. Hay que recordar que la más reciente de las fechas para cerámica "casi pulida" o tipo Gris Grueso Pulido es de 940 d.C., de manera que la fecha de 1000 d.C. para los comienzos de esta fase es razonable. Su final está indicado por la supuesta fecha de inicio de la ocupación inkaica.

Hay varios problemas que merecen un comentario en esta fase. En el momento en que Tarragó dio a conocer su trabajo, las fechas que se manejaban para la cerámica Dupont eran considerablemente más tardía de lo que se indica en la secuencia: en Chunchurí, cerca de Calama, Núñez fechó por C-14 una tumba con esta cerámica en $1490 \pm 100$ d.C. ${ }^{7}$. Trabajos posteriores en el río Loa y el salar de Atacama han confirmado los postulados cronológicos de Tarragó (CASTro et al., 1979: 8-9); hoy existen varias fechas C-14 y TL para esta cerámica que fluctúan entre 800 y 1000 d.C. (Serraccino, 1974b: 31 y pss.; Aldunate et al. Ms.). Por eso, las tempranas dataciones TL obtenidas para cerámica Dupont (variedad Ayquina) en San Pedro de Atacama ( $\mathrm{N}^{\circ} 32$ y 36) no debieran extrañar. Por lo demás, su asociación a materiales Tiwanaku $\left(\mathrm{N}^{\circ} 32\right)$ y a la alfarería "casi pulida" ( $\left.\mathrm{N}^{\circ} 36\right)$ refuerza esta ubicación cronológica. Las tempranas dataciones por C-14 (NúNez, 1976: 106-107) y TL ( ${ }^{\circ} 34$ y 35) para la cerámica Rojo Violácea, por otra parte, plantean un doble problema: primero, porque al igual que la cerámica Dupont, su comienzo parece ser bastante más antiguo de lo que

\footnotetext{
${ }^{7}$ Existe otra fecha C-14 tard́a para cerámica Dupont, esta vez del poblado de Quinchamale, en el Alto Loa (1470 \pm 80 d.C.).
} 
los investigadores están dispuestos a admitir; y segundo, porque dichas fechas, al igual también que en el caso Dupont, indican contemporaneidad con las influencias de Tiwanaku y con las últimas expresiones de la cerámica "casi pulida". Se produce así un traslape con la fase $V$ que no es fácil interpretar, sobre todo considerando las ambigüedades que existen en la fase VI.

Sin pronunciarnos por los aspectos de fondo, al parecer estas manifestaciones tempranas de los tipos Dupont/Ayquina y Rojo Violáceo expresan el arribo de una nueva tradición alfarera a San Pedro de Atacama, en plena fase $V$ y en contemporaneidad con las últimas influencias de Tiwanaku.

La cerámica Dupont/Ayquina, presente desde Pica hasta los altos valles calchaquíes, pero de mayor raigambre en el río Loa, aparece hoy como un tipo de tan escasa variación, que al observarla es imposible decir si se trata de una vasija de fines del milenio pasado, de comienzos de éste o contemporánea con la ocupación inkaica. Es necesario, por esto, estudiar acuciosamente la variabilidad de sus atributos, ya que sólo así se podrán discriminar sus cambios a través del tiempo.

En cuanto a la cerámica Rojo Violácea, Tarragó (ibíd.; 133) dice que tiene una baja representación en los cementerios de San Pedro de Atacama, hasta el punto que nos sentiríamos tentados a concluir que la tradicional caracterización de la fase inmediatamente preinkaica por medio de esta cerámica (LE PAIGe, 1963a; Orellana, 1962, 1964; Núñez, 1965; Bıttman et al., 1978) es poco sostenible hoy en día. Sabemos, no obstante, que Le Paige en sus excavaciones no daba preferencia a los cementerios de este período (TORREs, comunicación personal 1983), circunstancia que podría dar cuenta de la baja frecuencia de la cerámica Rojo Violácea en las colecciones del Museo. Además, los sitios habitacionales del período presentan esta cerámica en grandes cantidades, hecho que no se compadece con la aseveración de Tarragó y menos con la que nos sentíamos tentados a formular (cf. Serraccino, 1974).

Respecto a la ausencia de fechas TL para los siglos inmediatamente previos a la irrupción inkaica, esta situación responde a la subrepresentación de los materiales de esta época en el Museo; también a fallas en el proceso de selección de las muestras, ya que no contamos con información precisa (relación de contextos, por ejemplo) que nos garantizara un muestreo completo de esta fase. En cualquier caso, éste no es un problema demasiado importante para los propósitos de este trabajo: las cerámicas Dupont/Ayquina y Rojo Violácea se manufacturaban durante el episodio inkaico, tal como lo demuestran las pocas asociaciones de tumbas de la época disponibles en el Museo. Por lo tanto, sería rebuscado suponer que estos patrones alfareros perdieron vigencia en San Pedro de Atacama con posterioridad a las más recientes fechas $T L\left(N^{\circ} 39\right.$ y 40$)$, para recuperarla 300 años después.

Comentario aparte merecen las grandes vasijas de Solor-4 (LE PAIGE, 1964: Lám. 15l, fig. 2). Por su asociación con cerámicas Rojo Violáceas y "Colla Pacajes del altiplano" (tipo Hedionda, de Lípez y Toconce), fueron situadas entre 1200 y 
1240 d.C. (ibíd.: 84). Sin embargo, una de ellas fechada por nosotros dio una data insólitamente temprana ( $\left.\mathrm{N}^{\circ} 31\right)$. Tal hecho es aún más intrigante si consideramos que las estructuras habitacionales dentro de las cuales se encontraban enterradas dichas vasijas, recuerdan mucho las descripciones de Gerónimo de Bibar (1966 (1558): 13-14) de las viviendas de San Pedro de Atacama en el siglo xvi. La persistencia, casi sin modificaciones, de un patrón de asentamiento durante 750 años es algo difícil de concebir, por lo que es necesaria una mayor investigación y, desde luego, nuevas dataciones. Aunque en el contexto de discusión de esta fase, la fecha no es aberrante, podría darse el caso que, tal como lo insinuara Le Paige (ídem.), las grandes vasijas no sean contemporáneas con las estructuras habitacionales, echando por tierra la analogía que vemos entre estas ruinas y la descripción de Bibar (nótese en Bibar la referencia a grandes tinajas para la chicha).

La fase VIII, correspondiente a la ocupación inkaica no fue testeada, pues es obviamente correcta.

\section{Conclusiones y Recomendaciones}

De acuerdo al test por TL, la secuencia general de Myriam Tarragó para el estadio Cerámico de San Pedro de Atacama es, en esencia, correcta, particularmente en las características ceramográficas de las fases segregadas y en la posición relativa de la mayoría de ellas (Cuadro 3). Naturalmente, el trabajo de phasing debe continuar, sobre todo mediante la discriminación de subfases. La secuencia de Tarragó representó un importante avance respecto de las secuencias elaboradas en la primera mitad de la década del ' 60 , con fases que muchas veces cubrían segmentos no superiores a 200 años dentro de un lapso total de 12 siglos. Hoy, sin embargo, el lapso excede los 18 siglos y las fases de Tarragó si bien son en general correctas, cubren segmentos considerablemente mayores. Por eso pensamos que la identificación de subfases es una tarea prioritaria en el futuro inmediato, especialmente si pretendemos conocer la secuencia de detalle de los procesos culturales más sustantivos acaecidos en la región.

Como conclusiones más específicas, la fase I debe permanecer como hipotética a la espera de mayores datos, sin perjuicio de lo cual, podría finalizar 600 años antes de lo previsto por Tarragó; la fase II requirió de algunos agregados, desarrollándose entre 300 a.C. y 100 d.C.; la fase III es correcta en cuanto a su contenido, pero se desarrolló entre 100 d.C. y 400 d.C.; la fase IV también es correcta en cuanto a su contenido, pero su desarrollo ocurrió entre 400 d.C. y 700 d.C.; la fase $V$ es igualmente correcta, sin embargo, su desarrollo es entre 700 d.C. y 1000 d.C.; la fase $V 1$ parece estar en conflicto con las evidencias y, en nuestra opinión, debería omitirse de la secuencia; la fase VII es correcta en contenido y cronología, desarrollándose entre 1000 d.C. y 1470 d.C.; y la fase VIII es obviamente correcta.

Las discrepancias entre los postulados cronológicos de Tarrago y la nueva 
cronología proporcionada por el test, eran esperables, dado que en el lapso transcurrido desde 1964 se han sucedido nuevas investigaciones en la región y, sobre todo, los métodos de datación absoluta han llegado a ser cada vez más refinados y ocupados con mayor asiduidad.

El objetivo que nos habíamos trazado, de actualizar al menos en parte la secuencia, se cumplió tanto con estos ajustes cronológicos, como también por medio de la consideración de los hallazgos arqueológicos omitidos por la autora o bien posteriores a 1964 .

Como recomendación, se sugiere sustituir la denotación de las fases con números romanos consecutivos usada por Tarragó y otros, por una basada en sitio-tipos. Esto en atención a los siguientes argumentos: 1) la escasa documentación disponible para la fase 1, que bien podría desaparecer como tal, o bien corresponder en el futuro a dos o más fases iniciales; 2) la omisión de la fase VI, que rompe el esquema ordinal; 3) la existencia de un aparente episodio de discontinuidad cultural, particularmente entre el desarrollo anterior al 700 d.C. y el posterior al $1000 \mathrm{~d}$.C., que podría interpretarse como el término del complejo San Pedro y el inicio de un nuevo complejo cultural en la región; y 4) las confusiones que se producen entre las fases de Tarragó y aquellas de las secuencias del ' 60 . En el Cuadro 3 se incluye una propuesta en este sentido, siguiendo previas sugerencias de Núñez (1976: 118).

Siempre hemos creído que la sección final de un artículo es el mejor lugar para relativizar los resultados de una investigación. Una sobrevaloración de los resultados del test puede llevar, a la vuelta de unos años, a simplificaciones similares a las que se criticaron en la introducción de este trabajo. Debemos admitir que la investigación tuvo limitaciones y es aconsejable tenerlas en cuenta a la hora de utilizar o emular la experiencia. Por ejemplo, salvo las fechas 6 y 30 , que provienen de sitios habitacionales, el resto data materiales exclusivamente funerarios, y sabemos que rara vez hay una correspondencia "uno a uno" entre tales materiales y aquellos procedentes de habitaciones; sólo la complementación de secuencias funerarias con secuencias habitacionales, permitirá obtener un cuadro más completo de la historia cultural del salar de Atacama. Otra limitación es que cerca del $50 \%$ de las cerámicas fechadas procede de un único cementerio, el de Toconao Oriente, lo cual pudo representar un sesgo en la investigación difícil de evaluar; aparte de ser el único cementerio que no yace en San Pedro de Atacama (dista $34 \mathrm{Km}$ al sureste), exhibe pobres condiciones de preservacion para los materiales perecibles (matriz de arena muy permeable a la humedad), hecho que quizás explique la relativa ausencia de artefactos de madera y otros, tan útiles para cruzar información entre tumbas ${ }^{8}$. Una última limitación que nos

${ }^{8}$ El énfasis en Toconao Oriente, se debe a que en este cementerio se halla representado un largo periodo, con la ventaja de que, a diferencia de lo que hiciera en otros cementerios, Le Paige se preocupó aquí de marcar con el número de la tumba cada una de las piezas del contexto, por corriente u ordinaria que fuese. Al no estar marcada la 
parece importante destacar, es que Le Paige excavaba de preferencia tumbas con cerámica negra pulida (en sentido amplio); de alli, al parecer, que las fases I, II, VII y VIII se encuentren subrepresentadas en el Museo y, además, que se hallen escasamente documentadas en términos de asociaciones funerarias, circunstancia que representaría otro sesgo en nuestra investigación.

Más adelante esperamos procesar las 15 muestras restantes, lo que probablemente no implicará cambios demasiado radicales respecto a estas conclusiones, pero contribuirá a mejorar la cronología y a aumentar la confianza en este estudio. Quizás un nuevo programa masivo de datación por TL, con énfasis en problemas puntuales dejados en evidencia por nuestra investigación, reporte buenos dividendos, especialmente en lo que concierne a las subfases. En todo caso, las 43 fechas TL presentadas en este informe proporcionan un marco cronológico-cultural más adecuado para la actual arqueología del salar de Atacama, y posiblemente permitirán reordenar la cronología y secuencia de las otras regiones atacameñas.

Una conclusión más amplia y general de este estudio, es que la experiencia llevada a cabo aquí puede repetirse en otros lugares con problemas y condiciones similares, dando, de paso, un renovado y original uso a colecciones cerámicas depositadas por largo tiempo en museos y otras instituciones. Programas de datación para colocar a prueba cronologías y secuencias previas, como el realizado en San Pedro de Atacama, son factibles de hacer casi inmediatamente en el extremo norte de Chile y serían de inestimable ayuda para los arqueólogos que trabajan en los Andes Centro Sur. Arica es un caso paradigmático en este sentido y -en un ámbito más pequeño- lo propio se puede decir de la Colección F. Max Uhle de Pisagua. El Norte semiárido, desde luego, también presenta problemas y condiciones ad hoc para un programa de esta naturaleza. Incluso, con las adaptaciones del caso, un programa de fechamientos por TL podría representar una ayuda decisiva en la construcción de la tan esperada secuencia cultural de la Araucanía...

\section{Agradecimientos}

Los fechados TL y la medición de los valores de concentración de Th, $\mathrm{U}$ y $\mathrm{K}_{2} \mathrm{O}$, fueron financiados por el grant $\mathrm{N}^{\circ} 4505$, otorgado en 1984 a José Berenguer por The Wenner-Gren Foundation for Anthropological Research, Inc. Se agradece la supervisión dada para este grant por don Hans Niemeyer, Director del Museo Nacional de Historia Natural. Estos agradecimientos son extensivos a

totalidad de las piezas en varios de los más importantes cementerios excavados hasta antes de 1970, muchas de las asociaciones de tumba que Tarragó estudió en 1964 se perdieron definitivamente. Luego, cementerios con un registro como el de Toconao Oriente (que son muy pocos), ofrecen hoy una invalorable oportunidad de reconstruir parcialmente el estudio de Tarragó. 
Leandro Bravo y Antonietta Costa (Instituto de Investigaciones Arqueológicas, U. del Norte), y a Ana María Barón y Loreto Suárez (Sociedad de Arte Precolombino Nacional), por proporcionarnos materiales e información de sitios en estudio. Los funcionarios auxiliares del Museo Arqueológico R.P. Gustavo Le Paige merecen una mención aparte en estos reconocimientos, por la diligente colaboración que prestaron durante la selección de las muestras. El reconocimiento es también para Carole Sinclaire (Museo Chileno de Arte Precolombino), por su solícita e invalorable ayuda en esa etapa del trabajo. Estas palabras de agradecimientos serían incompletas si no mencionáramos la colaboración prestada por Myriam Tarragó, quien, sin proponérselo, coincidió brevemente con nuestra estada en San Pedro de Atacama, dándonos decisivas aclaraciones sobre su trabajo y discutiendo con nosotros algunos aspectos de esta investigación.

\section{REFERENCIAS}

Aitkens, M.J. "Thermoluminiscent age evaluation and assessment of error limit: revised system". Archaeometry 18, 1976, pp. 233-238.

Aldunate, C. et al. Cronología y asentamiento en la región del Loa Superior. Trabajo presentado al X Congreso de Arqueología Chilena, Arica 5 al 10 de agosto, 1985.

BELL, W.T. "Thermoluminiscent dating: radiation dose-rate data". Archaeometry 21, 1979, pp. 243-245.

Benavente, A. Chiuchiu-200: una comunidad pastora temprana en la provincia de El Loa (II Región). Trabajo presentado al IX Congreso de Arqueología Chilena, La Serena, noviembre de 1982.

Berenguer, J. Hallazgos La Aguada en San Pedro de Atacama, norte de Chile". Gaceta Arqueológica Andina 12 [Lima] 1984, pp. 12-14.

Bibar, G. DE, Crónica y relación copiosa y verdadera de los reynos de Chile. Santiago. Fondo Histórico y Bibliográfico José Toribio Medina, 1966.

Bittman, B. "Introducción: sintesis de la historia de los estudios atacameños". Actas del XIIV Congreso Internacional de Americanistas, Manchester 1982, pp. 1-52, 1984.

Bittman, B. Cultura atacameña. Santiago. Ed. Gabriela Mistral, 1978.

Bravo, L. y A. Llagostera. "Solcor-3: un aporte para el conocimiento del período de la cultura San Pedro comprendido entre el 500 y el 900 d.C.". ' Trabajo presentado al X Congreso de Arqueología Chilena, Arica, agosto de 1985.

Castro, V. et al. "Primeros fechados arqueológicos por termoluminiscencia en Chile: Toconce (Il Región)", Noticiario Mensual No 270, Museo Nacional de Historia Natural, Santiago, 1979 pp. 3-10.

Congreso Internacional de Arqueología de San Pedro de Atacama. "Resúmenes de actas del congreso y cuadros cronológicos". Anales de la Universidad del Norte 2 [Antofagasta], 1963, pp. 184-209.

Deza, A. y A. Román "La dosimetría termoluminiscente en arqueología”. Trabajo presentado al X Congreso de Arqueología Chilena, Arica, agosto de 1985.

García-Barcena, J. "Técnicas de fechamiento de interés arqueológico". Cuadernos de Trabajo, Apuntes para Arqueología I [México D.F.], 1974.

LE Palge, G. "Continuidad o discontinuidad de la cultura atacameña". Anales de la Universidad del Norte 2 [Antofagasta], 1963a, pp. 7-25.

Le PAige, G. "La antigüedad de una tumba comprobada por carbono I 4 y el ambiente que la rodea". Revista Universitaria 26 (Santiago), 1963b, pp. 167-176. 
Le Paige, G. "El Precerámico en la cordillera atacameña y los cementerios del período Agro-Alfarero de San Pedro de Atacama". Anales de la Universidad del Norte [Antofagasta], $\mathrm{N}^{\circ} 3,1964$, pp. 3-275.

Le PAige, G. "Tres cementerios indígenas de San Pedro de Atacama y Toconao". Boletin de Prehistoria de Chile (Número especial) [Santiago] 1973, pp. 163-187.

Le Paice, G. "Nuevas fechas radiocarbónicas de la zona de San Pedro de Atacama". Estudios Atacameños [Antofagasta] $\mathrm{N}^{\circ} 4,1976$, pp. 145.

Le Palge, G. Toconao Oriente. En Apuntes de Campo, manuscrito en depósito en Museo Arqueológico R.P. Gustavo Le Paige, San Pedro de Atacama.

Lumbreras, L. y E. Mujica. "50 años de investigaciones en Tiwanaku". Gaceta Arqueológica Andina [Lima] $\mathrm{N}^{\circ}$ ], 1982, pp. 6-7.

Llagostera, A. et al. "Investigaciones arqueológicas en Tulor-1". Trabajo presentado al Simposio de Arqueología Atacameña, San Pedro de Atacama, enero de 1983.

Mujıca, E. "Fechados radiocarbónicos para el altiplano del Titicaca y su esfera de interacción".

Núñez, L. "Desarrollo cultural prehispánico en el norte de Chile". Estudios Arqueológicos, Universidad de Chile [Antofagasta] $\mathrm{N}^{\circ} 1,1965$, pp. 9-35.

NúÑEz, L. "Recientes fechados radiocarbónicos del norte de Chile". Boletín de la Universidad de Chile [Santiago] $\mathrm{N}^{\circ}$ 50, 1966, pp. 51-56.

Núñez, L. "Registro regional de fechas radiocarbónicas del norte de Chile". Estudios Atacameños [Antofagasta], $\mathrm{N}^{\circ} 4,1976$, pp. 74-123.

Orellana, M. "La cultura San Pedro". Arqueología Chilena, Universidad de Chile [Santiago] $\mathrm{N}^{\circ} 3,1963$, pp. 3-43.

Orfllana, M. "Acerca de la cronología del complejo cultural San Pedro de Atacama". Antropología, Universidad de Chile [Santiago], No 2, 1964, pp. 96-104.

Orellana, M. "Tipos alfareros de la zona del río Salado". Boletín de Prehistoria de Chile, Universidad de Chile [Santiago] $\mathrm{N}^{\circ} 1,1968$, pp. 3-31.

Orellana, M. "Influencias de Tiwanaku en San Pedro de Atacama". Trabajo presentado al Simposio de Arqueología Atacameña, San Pedro de Atacama, enero de 1983.

Ponce, C. Tiwanaku: espacio, tiempo y cultura. $4^{a}$ edición [La Paz-Cochabamba] Editorial Los Amigos del Libro, 1981.

Pollard, G.C. The Cultural Ecology of Ceramic-Stage Settlement in the Atacama Desert. Columbia University, Doctoral Thesis published on demand by University Microfilm International, Ann Arbor, Michigan, 1970.

Rivera, M. "Cronología absoluta y desarrollo cultural prehispánico en el norte árido de Chile: un método numérico para construir períodos arqueológicos". Estudios Arqueológicos, Universidad de Chile [Antofagasta] (Número especial), 1980, pp. 146-165.

Komán, A. et al. Pontificia Universidad Católica de Chile TL Dates, 1983 (II). Ancient TL $N^{\circ}$ I, 1983, pp. 10-12.

Román, A. et al. Pontificia Universidad Católica de Chile TL Dates, 1984 (III). Ancient TL.

Serraccino, G. "Noticias". Estudios Atacameños, Universidad del Norte [Antofagasta], $\mathbf{N}^{\circ} 2,1974 a$, pp. 105-110.

Serraccino, G. "Cerámica de Guatín". Estudios Atacameños, Universidad del Norte [Antofagasta] $\mathrm{N}^{\circ} 2,1974 \mathrm{~b}, \mathrm{pp} .11-36$.

Tarragó, M. "Secuencias culturales de la etapa Agroalfarera de San Pedro de Atacama (Chile)". Actas y Memorias del XXXVII Congreso Internacional de Americanistas, Mar del Plata 1966, Buenos Aires, Vol. 2, 1968, pp. 119-145.

Tarragó, M. "Alfareria túpica de San Pedro de Atacama (norte de Chile)". Estudios Atacameños, Universidad del Norte [Antofagasta] $\mathrm{N}^{\circ} 4,1976$, pp. 37-73.

Tarragó, M. "Relaciones prehispánicas entre San Pedro de Atacama (norte de Chile) y 
regiones aledañas: la quebrada de Humahuaca". Estudias Atacameños, Universidad del Norte [Antofagasta] $\mathrm{N}^{\circ} 5,1977$, pp. 50-63.

Torres, C.M. “Tabletas para alucinógenos de San Pedro de Atacama: estilo e iconografla". Tesoros de San Pedro de Alacama, Museo Chileno de Arte Precolombino [Santiago], 1984. 